\title{
The mid-depth circulation of the northwestern tropical Atlantic observed by floats
}

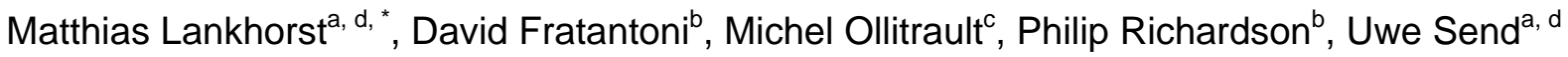 \\ and Walter Zenk ${ }^{\mathrm{a}}$

\footnotetext{
a Leibniz-Institut für Meereswissenschaften (IFM-GEOMAR), Kiel, Germany

${ }^{b}$ Woods Hole Oceanographic Institution (WHOI), Woods Hole, MA, USA

${ }^{\mathrm{c}}$ Institut français de recherche pour l'exploitation de la mer (Ifremer), Plouzané, France

${ }^{d}$ Scripps Institution of Oceanography (SIO), 9500 Gilman Drive, Mail code 0230, La Jolla, CA 92093-0230, USA
}

*: Corresponding author : Matthias Lankhorst, email address : $\underline{\text { mlankhorst@ucsd.edu }}$

\begin{abstract}
:
A comprehensive analysis of velocity data from subsurface floats in the northwestern tropical Atlantic at two depth layers is presented: one representing the Antarctic Intermediate Water (AAIW, pressure range 600-1050 dbar), the other the upper North Atlantic Deep Water (uNADW, pressure range 12002050 dbar). New data from three independent research programs are combined with previously available data to achieve blanket coverage in space for the AAIW layer, while coverage in the UNADW remains more intermittent. Results from the AAIW mainly confirm previous studies on the mean flow, namely the equatorial zonal and the boundary currents, but clarify details on pathways, mostly by virtue of the spatial data coverage that sets float observations apart from e.g. shipborne or mooring observations. Mean transports in each of five zonal equatorial current bands is found to be between 2.7 and 4.5 Sv. Pathways carrying AAIW northward beyond the North Brazil Undercurrent are clearly visible in the mean velocity field, in particular a northward transport of $3.7 \mathrm{~Sv}$ across $16^{\circ} \mathrm{N}$ between the Antilles islands and the Mid-Atlantic Ridge. New maps of Lagrangian eddy kinetic energy and integral time scales are presented to quantify mesoscale activity. For the UNADW, mean flow and mesoscale properties are discussed as data availability allows. Trajectories in the UNADW east of the Lesser Antilles reveal interactions between the Deep Western Boundary Current (DWBC) and the basin interior, which can explain recent hydrographic observations of changes in composition of DWBC water along its southward flow.
\end{abstract}

Keywords: Floats; Tropical Atlantic; Antarctic Intermediate Water; North Atlantic Deep Water; Equatorial currents 


\section{${ }_{24} 1$ Introduction}

This paper considers the area of the open Atlantic Ocean north of $10^{\circ} \mathrm{S}$ and south of the tropic of cancer $\left(23.5^{\circ} \mathrm{N}\right)$, between $65^{\circ} \mathrm{W}$ and $30^{\circ} \mathrm{W}$, which we will refer to as the northwestern tropical Atlantic. The island chain of the eastern Lesser Antilles and the coast of South America limit the domain in the west and southwest, whereas the other boundaries are in the open ocean. Parts of the Mid-Atlantic Ridge cross the domain and, together with the American coastline, define a diagonal sub-basin aligned from the northwest to the southeast that is characteristic of the region. Fig. 1 (top panel) shows a map of the area that includes the geographic features referred to in the text. The middle and bottom panels show the spatial data coverage.

Two depth ranges will be considered: one represents the Antarctic Intermediate Water (AAIW), and the other the upper part of the North Atlantic Deep Water (NADW). The motivation for studying the circulation of the Atlantic at these depths is the involvement of the currents in the Meridional Overturning Circulation (MOC). The Atlantic MOC carries relatively warm water northward near the surface and cold water southward at depth. The resulting northward heat transport is seen as an important part of the climate system (Marshall et al., 2001). AAIW with its northward spreading is associated with the upper limb of the MOC, while NADW is the southward component. This study was initiated as a synergy of three field experiments with subsurface floats that drift with the surrounding water: $\mathrm{MOVE}^{1}$ originally based at IFM-GEOMAR, NBC ${ }^{2}$ Rings Experiment based at WHOI, and $\mathrm{SAMBA}^{3}$ based at Ifremer. The main objective of MOVE is monitoring the southward transport of NADW east of the lesser Antilles with moored sensors (Send et al., 2002). Floats were deployed to assist the interpretation of the mooring

\footnotetext{
${ }^{1}$ Meridional Overturning and Variability Experiment

${ }^{2}$ North Brazil Current

${ }^{3}$ Sub-Antarctic Motions in the Brazil Basin
} 
measurements in the early phase of the experiment. The NBC Rings Experiment investigated the NBC off of South America between roughly $5^{\circ} \mathrm{N}$ and $10^{\circ} \mathrm{N}$ (Fratantoni and Richardson, 2006). The main constituent of the upper limb of the MOC, the NBC carries waters in the upper $1000 \mathrm{~m}$ northward across the equator and sheds anticyclonic current rings in its retroflection (Johns et al., 2003). SAMBA intends to map out the circulation of the AAIW in the Brazil Basin with a large amount of floats, some of which are within the domain of this study. The areas where data were gathered in these three campaigns complement each other to span almost the entire northwestern tropical Atlantic. Publicly available float data from five other field campaigns were added to further enlarge the database (listed in table 2). The total data amount is 305 cumulative years of float data, and the largest individual contributing project is now Argo. None of the individual projects by itself except perhaps Argo in the near future is capable of a basin-wide treatment of the circulation at the resolution required to map out the relatively narrow current bands. The combination of multiple datasets makes this possible for the AAIW layer. Previous observations of the circulation patterns (e. g. Stramma and Schott, 1999) are based mostly on mooring or shipborne observations of velocity, which lack spatial resolution, or hydrographic and tracer observations, which are powerful yet only indirect measures of the circulation. Float observations can fill these gaps with area-wide direct velocity observations, and studies of the tropical Atlantic with floats by Boebel et al. (1999a) and Schmid et al. (2003) have shown updated schematics of the circulation. However, these were based on relatively small amounts of data, especially in the northwestern tropical Atlantic, which is addressed here. This paper mostly confirms the previous circulation schematics with estimates of the mean flow that are based on substantially improved data coverage, supported by pathways visible in a multitude of individual trajectories. From eddy-resolving float data, kinetic energy levels and time scales of the mesoscale field are presented. As for the uNADW layer, data coverage remains limited. Older SOFAR float 
data that have been discussed in the literature (Richardson and Schmitz, 1993; Richardson and Fratantoni, 1999) are included in this study, but the discussion focuses on new data east of the Lesser Antilles, which are brought into context with recent hydrographic observations by Steinfeldt et al. (2007). Where possible, mean flow and mesoscale properties are quantified for the uNADW layer as well.

AAIW is formed in subpolar regions around Antarctica, from where it is subducted and spreads throughout the South Atlantic (Talley, 1996; Stramma and England, 1999). Its most conspicuous path is along the shelf break off South America between roughly $27^{\circ} \mathrm{S}$ and $10^{\circ} \mathrm{N}$ in the aforementioned North Brazil (Under-) Current (NBC, NBUC, Stramma et al., 1995), also called the Intermediate Western Boundary Current (IWBC). Near the equator, the path of AAIW is complicated by bands of alternating zonal flow, which have been described by Ollitrault et al. (2006) in a precursor to this study, and earlier e. g. by Schmid et al. (2003). Stramma et al. (2005) present ship-based measurements within the domain that include data in the AAIW, and Boebel et al. (1999b) give a comprehensive account of the intermediate-depth equatorial currents in the earlier literature. The situation within $1^{\circ}$ of the equator is complicated by vertically alternating jets (e. g. Gouriou et al., 2001; Send et al., 2002; Schmid et al., 2005), the dynamics of which are not yet well understood. Fig. 1 (middle) schematically shows locations and directions of the NBUC and five equatorial current bands: the Northern and Southern Equatorial Intermediate Currents (NEIC, SEIC) flowing westward near $4^{\circ} \mathrm{N} / \mathrm{S}$, the Northern and Southern Intermediate Countercurrents (NICC, SICC) flowing eastward near $2^{\circ} \mathrm{N} / \mathrm{S}$, and the Equatorial Intermediate Current (EIC) flowing westward on average at the equator (seasonal cycles and reversals described e. g. by Ollitrault et al., 2006).

The main hydrographic characteristic of AAIW is a minimum in vertical salinity profiles, shown in fig. 2 with velocities from an LADCP (Lowered Acoustic Doppler Current Profiler) on two sections (data from Rhein et al., 2004, 2005). Current features captured 
by the LADCP data include the NBC, NEIC, NICC, EIC, SICC, and an eddy that Rhein et al. (2005) identify as an NBC ring. The minimum in salinity can be identified through the entire study domain, although its northern extent does not reach far beyond the tropics (e. g. Talley, 1996). Here, floats drifting at pressures between 600 and 1050 dbar will be interpreted as being in the AAIW. This choice agrees with the isopycnals shown in fig. 2, which in turn are used by Stramma and England (1999) and Rhein et al. (1995), although it includes upper Circumpolar Deep Water which is between approximately 900 and 1100 dbar.

In contrast to AAIW, NADW as a whole stems from convection and mixing processes in the polar and subpolar North Atlantic. Following the North American shelf break southward, it reaches the tropics as a Deep Western Boundary Current (DWBC, cf. figs. 1 (bottom) and 2), where it occupies pressure ranges between approximately 1200 and 3900 dbar (Rhein et al., 1995). More specifically, we will combine floats in the range 1200-2050 dbar as being in the upper NADW (uNADW), a common naming convention used e. g. by Curry et al. (1998, for more details, see Rhein et al. (1995)). In hydrographic measurements, this depth range is characterized by the highest salinity of the NADW (fig. 2). NADW too is subject to zonal current bands away from the DWBC in the equatorial region (Richardson and Fratantoni, 1999).

A current review of float technology, including all types of instrumentation exploited here, is given by Rossby (2007). Two positioning strategies have evolved for floats: acoustic floats are positioned acoustically while submerged, and profiling floats return to the surface periodically for satellite position fixes. Currents are derived from the displacements between successive fixes. Here, acoustic floats have one or two position fixes per day, which makes them eddy-resolving. Profiling floats, in contrast, are located typically every ten days and therefore do not resolve the mesoscale, but the larger number of them helps to map out the mean flow. Mean currents are derived from combining displacements 
between individual cycles of profiling floats, and acoustic trajectories sub-sampled at tenday intervals. The discussion of mesoscale variability is based on acoustic floats only. Typical eddy time scales will be shown to be shorter than ten days, so that successive float displacement cycles can be assumed statistically independent.

\section{Mean Flow Field}

\subsection{Mean Flow Derived from Float Observations}

\subsubsection{Antarctic Intermediate Water (AAIW)}

Fig. 3 shows a stream function derived from all available float displacements in the AAIW layer. The individual velocity measurements shown in fig. 1b were interpolated onto a grid of $0.5^{\circ}$ resolution, with Gaussian weights of standard deviation $50 \mathrm{~km}$. From these gridpoints, vorticity $\zeta$ was derived by central differences, and the stream function $\Psi$ was obtained by numerically solving ${ }^{4}$ the Poisson equation $\nabla^{2} \Psi=-\zeta$ on the domain shown in the figure. The boundary condition along the American shelf is a constant streamline (Dirichlet boundary condition), while the boundary conditions in the open ocean are defined through the velocity measurements themselves (Neumann boundary conditions). All flow features discussed below are also present in the raw gridded velocity data and therefore not artefacts of the streamline computation.

The resulting stream function clearly depicts the NBUC and the following five equatorial zonal flows as the features with the strongest currents: NEIC, NICC, EIC, SICC, and SEIC. The equatorial zonal flows have been discussed by Ollitrault et al. (cf. 2006). Assuming a layer thickness of $450 \mathrm{~m}$, the mean volume transports of the five equatorial

\footnotetext{
${ }^{4} \mathrm{MatLab}^{\mathrm{TM}}$ contains the algorithms in its "PDE toolbox" product.
} 
currents in the middle of the basin (longitudes from $40^{\circ} \mathrm{W}$ for the NEIC to $30^{\circ} \mathrm{W}$ for the SEIC) are approximately 3.2, 4.5, 3.2, 4.1, and $2.7 \mathrm{~Sv}$, respectively. Until recently, there has been doubt about the mere existence of these intermediate-depth zonal flows (Jochum and Malanotte-Rizzoli, 2003), which has been eliminated by successive observational (Schott et al., 2003; Schmid et al., 2003) and modelling studies (Eden, 2006). The positions of the NEIC and to some extent the NICC shift northward at short distances from the western boundary, in the case of the NEIC from near $4^{\circ} \mathrm{N}$ in the basin interior to $5^{\circ} \mathrm{N}$ at $45^{\circ} \mathrm{W}$. This shifted NEIC location is not reproduced by Schmid et al. (2003, their fig. 17). Stramma and Schott (1999, their fig. 6) generally show the NEIC too far north. The streamlines of the NICC and NEIC in these displacements (west of $40^{\circ} \mathrm{W}$ ) tend to follow the deep isobaths of the Ceará Ridge and the Amazon Cone, suggesting that these topographic features exert some guidance on the AAIW flow although they are at depths exceeding $3000 \mathrm{~m}$. At least it seems likely that the NEIC would continue along $4^{\circ} \mathrm{N}$ all the way to the western boundary if the ridge were not there. The inflow in the NBUC at $8^{\circ} \mathrm{S}$ is found to be $5.0 \mathrm{~Sv}$, which is in general agreement with the analysis by Schott et al. (1998). All transport values were obtained by integrating across the streamlines of fig. 3 and are listed in table 3 together with previous estimates.

Northwestward from the Guiana Plateau, the streamlines suggest a continuous flow of AAIW parallel to but mostly detached from the shelf break. This mean flow is not easily observed due to masking by the mesoscale eddy field (discussed in section 3), yet it seems to be the major pathway of AAIW west of $53^{\circ} \mathrm{W}$. From the Guiana Plateau to Barbados, this path resembles the advection of NBC rings (Fratantoni and Richardson, 2006; Johns et al., 2003; Goni and Johns, 2001). Consistent with these studies on NBC rings, which repeatedly show rings near or even around Barbados, fig. 3 shows northward flow to either side of the island with a larger portion west of it as would be expected of an anticyclone surrounding Barbados as it progresses northward. At $15^{\circ} \mathrm{N}$ north of Barbados, some 
northward flow remains close to but not as tightly concentrated at the boundary, while four streamlines fan out northeastward into the ocean interior. The location coincides with one where many NBC rings stall or cease to exist (Fratantoni and Richardson, 2006; Goni and Johns, 2001). Stalling of the rings can explain why hydrographic measurements (Rhein et al., 2005, or fig. 2 here) repeatedly find them there, and why the mean flow decelerates as documented by the fanning out of the streamlines. The separation of the streamlines from the western boundary at $15^{\circ} \mathrm{N}$ is also consistent with the hydrography, which shows the thickest layer of fresher water (fig. 2) or the highest concentrations of water from the southern hemisphere (Rhein et al., 2005) beginning at least $200 \mathrm{~km}$ offshore. In their analysis of water entering the Caribbean between the Lesser Antilles, Rhein et al. (2005) identify higher concentrations of southern waters in passages between the islands south of $15^{\circ} \mathrm{N}$, exactly where fig. 3 here finds the mean flow-presumably carrying the highest concentrations of AAIW - closer to the islands than it does further north. Northward transports across $16^{\circ} \mathrm{N}$ are $1.4 \mathrm{~Sv}$ in the interior pathway (east of $59^{\circ} \mathrm{W}$ but west of the Mid-Atlantic Ridge) and $2.3 \mathrm{~Sv}$ in the path closer to the boundary. Assuming that transport across $16^{\circ} \mathrm{N}$ happens by advection of remaining NBC rings, Rhein et al. (2005) derive a transport that agrees with these values (see table 3). We therefore interpret the mean flow in the AAIW layer from the Guiana Plateau onward as the translation of NBC rings, a concept introduced by Richardson et al. (1994) for near-surface data. At the northern limit of the domain (beyond $20^{\circ} \mathrm{N}$ ), the wider spacing of the streamlines and associated low speeds correspond with the northernmost extent of

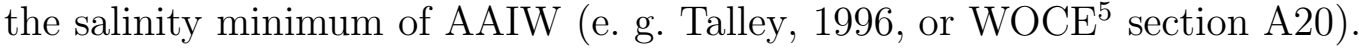

The remaining area apart from the equatorial and boundary regimes is characterized by very slow - if any - mean flow. Stramma and Schott (1999) have presented a circulation schematic of the entire tropical Atlantic for the AAIW layer (their fig. 6), based on

\footnotetext{
${ }^{5}$ Cf. e. g. http://www.ewoce.org
} 
measurements available then, i. e. before the availability of large float data amounts. Excellent agreement with respect to the equatorial and near-equatorial flow (EIC, NICC, SICC) is found between our fig. 3 and the schematic by Stramma and Schott (1999). However, they display the NEIC further north, and the SEIC is obscured in several branches of the South Equatorial Current and the mostly shallower South Equatorial Undercurrent. Their continued northward flow beyond the NBUC, which they refer to as the IWBC, enters the Caribbean between the southernmost Antilles islands, unlike what floats show here, and they show large inter-basin gyres between $5^{\circ}$ and $20^{\circ} \mathrm{N}$ where float data suggest insignificant mean flow. With the IWBC escaping into the Caribbean, their scheme cannot reproduce the flow towards Barbados and further north. Some of these discrepancies in the equatorial region, approximately $8^{\circ} \mathrm{S}$ to $5^{\circ} \mathrm{N}$, have been clarified in a similar schematic by Schmid et al. (2003, their fig. 17) based on float data included in this study. Schmid et al. (2003) adjust the position of the NEIC and simplify the zonal flow patterns around the SEIC to a degree that matches the findings presented here, although they rely on individual trajectories in some cases. However, they continue to include parts of an inter-basin, anticyclonic gyre north of the NEIC, which is not supported by the present study. We will update the schematics by Stramma and Schott (1999) and Schmid et al. (2003) in the conclusions at the end of the paper.

\subsubsection{Upper North Atlantic Deep Water (uNADW)}

Data density of the uNADW layer does not allow for a similar map of streamlines, but fig. 4 shows box-averaged mean velocities where data are available. Near the DWBC, the boxes were designed to follow the flow features as seen in individual trajectories (cf. fig. 9). In a broad area east of the Lesser Antilles (between $11^{\circ} \mathrm{N}$ and $19^{\circ} \mathrm{N}, 58^{\circ} \mathrm{W}$ and $46^{\circ} \mathrm{W}$ ), there is slow but prevalent westward mean flow of $0.8 \mathrm{~cm} \mathrm{~s}^{-1}$ with a standard error of $0.2 \mathrm{~cm} \mathrm{~s}^{-1}$. For a subset of this data (MOVE), the mean flow is even higher at $1.5 \mathrm{~cm} \mathrm{~s}^{-1}$ 
with the same standard error. This westward flow comes at least from near the MidAtlantic Ridge, possibly from further east, and connects with the southward DWBC near the Lesser Antilles. Steinfeldt et al. (2007) find a strong dilution of the DWBC between $16^{\circ} \mathrm{N}$ and $10^{\circ} \mathrm{N}$ based on tracer measurements, which can be explained by this inflow from the east. The origin of this westward flow is not obvious from the present dataset, but NADW has been observed to spread southward east of the Mid-Atlantic Ridge at latitudes between $35^{\circ} \mathrm{N}$ and $50^{\circ} \mathrm{N}$ (Speer et al., 1999; Bower et al., 2002; Machín et al., 2006). In the same latitudinal range, Paillet et al. (1998) and Getzlaff et al. (2006) discuss a southward path along the ridge. Hence we speculate that the westward flow observed by the floats is fed by a branch of uNADW that does not spread in the DWBC but rather via slower pathways along or east of the Mid-Atlantic Ridge.

Centered at about $15^{\circ} \mathrm{N}$ at the western boundary of the domain, a narrow recirculation cell is also present in the mean, which could be yet another reason for the dilution observed by Steinfeldt et al. (2007). Results from the SOFAR floats off South America, which have measured the boundary current and parts of the equatorial current system, have been published by Richardson and Fratantoni (1999) but are not well represented in fig. 4 due to data sparsity.

\subsection{Comparison with Other Measurements}

Several measurements with moored current meters exist in the study area with instruments within the AAIW and the uNADW layers. An overview of the locations of these moorings is included in fig. 1. Figures 5 and 6 show comparisons of mean velocities between float and mooring data across three sections. The sections were designed to be perpendicular to the shelf break. Float data within $167 \mathrm{~km}\left(1.5^{\circ}\right)$ to either side of the target sections (within $222 \mathrm{~km}$ or $2^{\circ}$ for the two southern uNADW sections) are used 
to compute across-section velocities. Float data are grouped into bins of $100 \mathrm{~km}$ width, and the figures show the bin averages, 95\% confidence limits, and the scattered cloud of individual float samples. Means and confidence intervals from moored sensors are superimposed. In all sections, the boundary currents are the most prominent features. Here, agreement between mooring and float data is probed to rebut the suspicion that interpretation of float data is flawed by systematic deviations between the two (Stokes Drift).

Fig. 5 shows results on the AAIW. Near the endpoints of the northernmost section (a), multi-year mooring records from MOVE and float data concordantly show zero mean flow. Mooring data from Johns et al. (1990, section b) show the northwestward NBUC with mean currents near $13 \mathrm{~cm} \mathrm{~s}^{-1}$ at the boundary, decreasing to almost zero $150 \mathrm{~km}$ out, in excellent agreement with the float data. Section (c) contains mooring data from Schott et al. (1993), which show a northwestward NBUC flanked by a southeastward flow. The float averages show the same features, generally with a stronger northwestward component, and disagreements are within the confidence limits. Section (c) in particular highlights how the basin-wide float coverage adds to the interpretation of the existing data, since the floats reveal the southeastward flow seen in the mooring data to be part of the alternating pattern of zonal flows in the equatorial region (the NICC in this case). The streamlines of fig. 3 (included in fig. 5) show how the NBUC flow at section (c) folds back in the NICC, is then re-established at section (b), and successively detrained in a recirculation within the Guiana Basin as well as fanned out away from the coast before reaching section (a).

Fig. 6 contains data from the same sections but within the uNADW. Section (a) has abundant multi-year mooring data from MOVE and also GAGE (2000-2002, Guiana Abyssal Gyre Experiment, M. McCartney, pers. comm.). In agreement with the float data, these show virtually no significant mean flow across the section except for the 
southward DWBC. The westernmost bin of float data, which contains the DWBC, is slightly biased to slower currents than those of the nearby moorings, because the floats only sampled the outer edge of the DWBC with no measurements as far west as the mooring location. The few float data available near the boundary in section (b) resemble the mooring measurements by Johns et al. (1990) and Colin et al. (1994) in that they show the DWBC near $10 \mathrm{~cm} \mathrm{~s}^{-1}$. In section (c), mooring results by Schott et al. (1993) and float data consistently depict the DWBC mean between 20 and $30 \mathrm{~cm} \mathrm{~s}^{-1}$. A discrepancy just outside the confidence limits for the outermost mooring coincides with a shortened data record of the moored sensor which was also significantly shallower than most of the floats there.

Generally, agreement between the mooring and float observations is surprisingly good given the sparse float data coverage in the uNADW and the fact that the measurements were taken years apart in several instances. Good agreement also exists with mooring results by Johns et al. (1998). Table 3 compares transport estimates from different studies, from which a coherent estimate of the transports in the equatorial zonal flows and the boundary current in the AAIW emerges. High values for the EIC and to a lesser extent the SICC and NICC in early estimates by Schott et al. (1998) are explicable by the timing of the shipborne measurements relative to the annual cycle, which occured at times confirmed to have maximum transport in the EIC (October and November) and the NICC/SICC (June, Ollitrault et al., 2006, their fig. 4). The subsequent analysis of a larger shipborne dataset (Schott et al., 2003) brings these values much closer to the float-based estimates, with the remaining differences consistent with the (reduced, but still existing) biases in timing of the ship cruises, which have gaps in July, September, and December: high bias in the ship-based values for the NEIC correspond to maximum transport in the well-sampled period February-May, low bias in the SICC and NICC to lack of measurements in July, and high bias in the EIC to oversampling in October 
and November. Nonetheless, the differences between transports from the ship-based data (Schott et al., 2003) and the present study are small, and indeed of the same magnitude as differences between the present study and that by Ollitrault et al. (2006), which use the same dataset but differ computationally. We therefore conclude that results on the mean currents obtained from the float measurements are not significantly biased versus their Eulerian counterparts in the moorings or ship-based measurements.

\section{Mesoscale Variability}

Section 2 has shown that the observed AAIW mean velocities in the inner basins away from the equatorial region are very low. However, many individual float trajectories have relatively high velocities: e. g. for the MOVE floats in the AAIW layer, where the mean velocity is almost zero, the rms value of the ten-day displacement velocities is still $4.4 \mathrm{~cm} \mathrm{~s}^{-1}$, and more than $20 \%$ of the ten-day velocities exceed $10 \mathrm{~cm} \mathrm{~s}^{-1}$. This clearly motivates a closer look at the mesoscale velocity field. Because of their high temporal resolution (at least one position per day), only the acoustically tracked floats are used for this. Fig. 7 (top panel) shows the data coverage achieved with acoustic floats in the AAIW. The lower data density in the uNADW is already indicated in fig. 1.

From floats, the mesoscale field is appropriately described by the Lagrangian eddy kinetic energy (EKE) and the Lagrangian integral time scale $\left(\mathrm{T}_{\text {int }}\right)$. To estimate these, trajectories were split up in windows of $80 \mathrm{~d}$ duration with a $90 \%$ overlap (i. e. 72 d). For each window, the mean and a linear trend were removed from the velocities, and the variances $\sigma_{\ldots}^{2}$ of the velocity data $u, v$ define an EKE measurement per:

$$
\mathrm{EKE}=\frac{1}{2}\left(\sigma_{u}^{2}+\sigma_{v}^{2}\right)
$$

With the normalized autocorrelation of $u$ at time lag $\tau$ written as $R_{u}(\tau)$, the Lagrangian 
integral time scale were computed for each window from:

$$
T_{\mathrm{int}, u}=\int_{0}^{\infty} R_{u}(\tau) \mathrm{d} \tau
$$

Here, $\mathrm{T}_{\text {int }}$ is averaged over $u$ and $v$, and the integrations are only carried out to the first zero-crossings of $R_{\ldots}(\tau)$. Lagrangian length scales can then be derived as the product of $\mathrm{T}_{\text {int }}$ and $\sqrt{\mathrm{EKE}}$. Details of the computation are identical to those used by Lankhorst and Zenk (2006, their appendix b).

Figure 7 shows the EKE and $\mathrm{T}_{\text {int }}$ for the AAIW layer in the northwestern tropical Atlantic, spatially filtered and interpolated onto a $1^{\circ}$-by- $1^{\circ}$ grid. EKE is highest near the boundary (exceeding $100 \mathrm{~cm}^{2} \mathrm{~s}^{-2}$ ) and decreases to values below $50 \mathrm{~cm}^{2} \mathrm{~s}^{-2}$ in the interior. Increased EKE near $12^{\circ} \mathrm{N}$ and $58^{\circ} \mathrm{W}$ is caused mainly by the two intense cyclones discussed in section 4.1. A small area between Barbados and the southernmost Windward Islands (Tobago Basin, centered at about $60.5^{\circ} \mathrm{W}$ and $12.5^{\circ} \mathrm{N}$ ) is separated from the open Atlantic by a submarine ridge and also has high EKE, but the area is sampled by just one float. Another broad maximum of EKE near $100 \mathrm{~cm}^{2} \mathrm{~s}^{-2}$ is located between the equator and $5^{\circ} \mathrm{N}$, west of about $40^{\circ} \mathrm{W}$. This is the region where floats indicate energetic interactions between the equatorial currents (NICC and EIC) and the boundary current.

The Lagrangian integral time scale is longest in the interior basin away from the equator and reaches values of typically just below $10 \mathrm{~d}$, which would connect well with findings by Rossby et al. (1986). Closer to shore and within the equatorial region, shorter time scales around $5 \mathrm{~d}$ are observed. The float in the Tobago Basin has also experienced short time scales. Computed length scales are 20-30 km for the open ocean areas, exceeding $50 \mathrm{~km}$ in the boundary current regime off the Amazon, and near $50 \mathrm{~km}$ in the equatorial area offshore. These length scales correspond to about $35 \%$ of an eddy diameter if one assumes perfectly circular motion. Hence, typical eddy diameters in the 
off-equatorial northwestern tropical Atlantic are near $70 \mathrm{~km}$, and fluctuations related to the NBUC larger than $140 \mathrm{~km}$.

In the uNADW layer, the following mesoscale properties are observed (not shown in figure): along $16^{\circ} \mathrm{N}$ east of the Lesser Antilles (along section (a) of fig. 6), EKE values decrease from above $30 \mathrm{~cm}^{2} \mathrm{~s}^{-2}$ near the western boundary to below $10 \mathrm{~cm}^{2} \mathrm{~s}^{-2}$ in the basin interior. $\mathrm{T}_{\text {int }}$ averages between 7 and $9 \mathrm{~d}$ along this section. North of the Amazon delta (approx. along section (b) of fig. 6), SOFAR floats measured significantly higher EKE values of $110 \mathrm{~cm}^{2} \mathrm{~s}^{-2}$ near the shelf, which also decrease to below $10 \mathrm{~cm}^{2} \mathrm{~s}^{-2}$ further out (Richardson and Schmitz, 1993). $\mathrm{T}_{\text {int }}$ here seems to systematically increase from $7 \mathrm{~d}$ near the boundary to almost $10 \mathrm{~d}$ offshore. Corresponding length scales tend to be smaller than in the AAIW layer, mainly because of the lower EKE, but are also in the range of 20-70 km with lowest values in the ocean interior and highest values near the boundaries.

\section{Detailed Studies}

\subsection{Selected Trajectories}

In the following paragraphs, we highlight a selection of individual trajectories that show peculiar circulation patterns or are representative of features discussed in the previous sections.

\subsubsection{Antarctic Intermediate Water (AAIW)}

Fig. 8 shows trajectories from acoustic floats in the AAIW only, from which those with poor tracking geometry or acoustic performance have been removed manually. The seemingly chaotic superposition of the trajectories highlights the role of the mesoscale field in 
the area, as discussed in section 3. Within this complex setting, the following features can be identified at closer look:

One float moved southeastward along the shelf break west of the Guiana Plateau (label A in fig. 8), after heading northwestward further offshore. This suggests that the NBUC as a boundary current typically does not reach this far northwest, favoring the idea of a mean flow that detaches from the boundary at Guiana Plateau. The same pattern was visible in fig. 3, and the interpretation is that the mean flow is produced by rings and eddies shed from the NBUC.

North of there (label B in fig. 8), two floats independently measured intense smallscale cyclonic eddies, which make the trajectories show looping behavior for long times (exceeding 10 months). The high swirl velocities and the persistence of these two eddies stand out drastically from the data set. One of them has been thoroughly discussed by Fratantoni and Richardson (2006), yet the occurence of a second one (from the SAMBA data at a different time) suggests that such features might be common in the area. The EKE values in fig. 7 are greatly elevated in this area because of these two eddies.

Only two floats penetrated into the Caribbean, through the passage between Martinique and Dominica (approx. $15.1^{\circ} \mathrm{N}$, label $\mathrm{C}$ in fig. 8), documenting this as a possible but rather unlikely route for AAIW. Once in the Caribbean, the floats lost acoustic tracking, and the figure shows only their surface positions after their missions were finished. It is surprising that no other floats moved into or back out of the Caribbean, since e. g. Rhein et al. (2005) and Kirchner et al. (2008) document ample flow in either direction through various passages, and the one between Martinique and Dominica does not stand out in any way in their data. They find significant interannual variability in the transports, and with the relatively low number of floats approaching the islands, the most likely explanation is that no float was in the right location at the right time to be advected past 
the islands. However, perhaps the topography around the Tobago and Barbados Basinsalbeit deeper than the AAIW level - shields the passages south of St. Lucia from the open Atlantic, while the northern ones remain more exposed.

Within $5^{\circ}$ of the equator, floats mainly drift zonally in the five current bands discussed in section 2 (NEIC, NICC, EIC, SICC, SEIC). One exemplary trajectory for each current band is highlighted in fig. 8. Superimposed on the zonal motions, most trajectories have wave-like patterns (found also by Boebel et al., 1999b), the dimensions of which are described by the time and length scales in section 3 .

At the shelf break, only two floats cross the equator (label E), which is again surprising given the idea of a boundary current. However, the area immediately upstream of the equator (approx. south of the equator and west of $40^{\circ} \mathrm{W}$ ) is only sparsely populated with floats, because most are removed from there by the SICC. Together, this suggests that AAIW spreads northward preferably via excursions in the zonal flows rather than on a continuous path along the boundary.

\subsubsection{Upper North Atlantic Deep Water (uNADW)}

Fig. 9 shows sample trajectories from the uNADW layer. The SOFAR floats that comprise most of the data in the southeastern portion of the domain have already been discussed by Richardson and Fratantoni (1999) and initially Richardson and Schmitz (1993), who describe pathways within the southeastward DWBC and zonal excursions into the ocean interior and back.

Further north (between roughly $13^{\circ} \mathrm{N}$ and $21^{\circ} \mathrm{N}$ ), all MOVE and ACCE floats in the uNADW had at least some tendency to drift westward in the open ocean (label $\mathrm{F}$ in fig. 9). This broad westward flow is also present in the mean field discussed in section 2 . From the trajectories, it seems possible that the westward flow originates east of the Mid- 
Atlantic Ridge. Five of the MOVE floats were eventually caught in the southward-flowing DWBC. The location where they merge with the DWBC is consistent with the strong dilution of uNADW between $16^{\circ} \mathrm{N}$ and $10^{\circ} \mathrm{N}$ as observed by Steinfeldt et al. (2007).

When the DWBC reaches a latitude of approx. $12^{\circ} \mathrm{N}$ southeast of Barbados, the continental slope becomes less steep, and the few floats available show a tendency to diverge at this location (label G in fig. 9). This has also been proposed by Steinfeldt et al. (2007) as a reason for water mass dilution. Because of this detraining from the DWBC, only one MOVE float actually reaches the longitude of $50^{\circ} \mathrm{W}$ via the DWBC and thereby connects with the area sampled by the SOFAR floats a decade earlier (label H in fig. 9). The other four completed their pre-programmed life spans before traveling this far.

In the Tobago and Barbados Basins between Barbados and Trinidad, which are separated from the deep ocean by a system of ridges, one of the profiling floats was subject to erratic flows which trapped it "inshore" of the DWBC for more than half a year (label $\mathrm{J}$ in fig. 9). The long stagnation time in this area suggests that the Tobago and Barbados Basins contain older water masses at this depth, although the relatively young uNADW water flows by in immediate vicinity.

Two floats recirculated offshore of the DWBC northeast of Barbados in a loop approximately $70 \mathrm{~km}$ wide and $400 \mathrm{~km}$ long (label $\mathrm{K}$ in fig. 9). This forms a narrow recirculation cell, the velocities of which are significantly larger than those of the basin-wide westward flow at the same latitude, and yet another pathway to dilute water masses of the DWBC.

Fig. 10 shows a synoptic one-month snapshot of three MOVE floats that paralleled each other in the DWBC with the inshore ones fastest, highlighting the horizontal velocity shear between them. Extrapolating from this shear, the span of the southward DWBC is estimated as $150 \mathrm{~km}$ (zero-crossing), consistent with the width of about $100 \mathrm{~km}$ seen in 
fig. 6 at section (a).

\subsection{Interaction between the Boundary Current and the Equa- torial Currents}

Fig. 3 in section 2 has shown that the strongest features of the mean circulation in the AAIW are the five alternating zonal currents of the equatorial region and the western boundary current. Here, we will take a closer look at exchange between these currents, both in the mean field and individual trajectories, which we will find to be generally consistent but with additional pathways suggested by some trajectories.

Bearing in mind that the process of computing the stream function might have introduced uncertainties in the actual pathways of the water masses, fig. 3 suggests the following about interactions between the boundary and the equatorial currents, from south to north: most of the SEIC plus a small fraction of the NBUC recirculate eastward in the SICC. In the eastern half of the basin (east of $35^{\circ} \mathrm{W}$ ), additional input into the SICC comes from the EIC to its North. All streamlines from the EIC that reach the western boundary are brought eastward again in the NICC. The NICC also detrains large portions (all but two streamlines) from the NBUC. The westward NEIC re-establishes the boundary current as it approaches the shelf break.

To further investigate sources and sinks of the waters in the equatorial currents near the western boundary, fig. 11 displays trajectory segments of floats that have passed through certain boxes within the equatorial current bands of the AAIW layer. There is one box per current band, and trajectories of up to $80 \mathrm{~d}$ prior to entering and after leaving the boxes are shown. Generally, the zonal velocity component of the individual float trajectories meets the expectations from the mean field, which is apparent from the different colors (red vs. green) concentrating east or west of the boxes. 
Six trajectories leading into the NEIC box do so from the east, two after being ejected from the NICC and the others more directly from the east but with significant meandering motions, likely tropical instability waves (Richardson and Fratantoni, 1999). Two come from the south, one of them directly from the EIC. Two come from the north and none from the west. After leaving the NEIC box, most trajectories lead northwestward, consistent with the NBUC: five trajectories exit to the west, three to the north, one to the south, and none to the east. Two of these trajectories, eventually go southand then eastward in the NICC.

The majority of floats entering the NICC box do so through its northern or southern edges with a significant eastward velocity component (six from the north, eight from the south). Two trajectories enter from the west, and none from the east. Six floats entering the NICC box had previous westward motion in the EIC, and then turned northward to join the NICC. At least five tracks from the NBUC into the NICC are documented, along with one trajectory that was along the boundary but in the opposite direction before reaching the box. Three trajectories exit the NICC box through the northern, five through the southern, seven through the eastern and none through the western edge. Most of the trajectories leaving the NICC box stay in the eastward NICC jet, with further wave-like meanders. The concentration of inflowing trajectories in two locations at the northwestern and southwestern corners, and of the outflowing ones at the eastern boundary represents standing or quasi-permanent meanders of the NICC. An anticyclonic circulation centered around $2^{\circ} \mathrm{N}, 44^{\circ} \mathrm{W}$ is observed in several instances and seems to be a typical motion in this area where the NICC, EIC, and NBUC interact (cf. also fig. 8).

All floats entering the EIC box do so in meandering motions from the east: three through the eastern, one through the northern, and three through the southern edge. Four leave the box through the western edge, and one each through the northern and southern edge. Two of these drift northward, then eastward in the NICC, three feed the 
NBUC, and one follows a southward, and then eastward path resembling either a reversal of the EIC or the northernmost edge of the SICC.

Trajectories entering the SICC box count as follows: seven through the northern, three through the southern, nine through the western, and one through the eastern edge. Three of these come from the EIC, two from the SEIC, and four from the boundary regime where they had northwestward motion. Two trajectories had an opposite flow direction when they were near to the boundary. Exit from the SICC box takes places predominantly with an eastward component. Seven trajectories leave through the northern edge, only one of which winds up in the westward EIC. Both trajectories that leave through the southern edge head westward consistent with the SEIC. Ten exit the box through the eastern edge, three of which recurve south-, then westward in the SEIC. Many others again show the characteristic meandering motions mentioned before.

The SEIC box receives two trajectories through the northern, three through the southern, and nine through the eastern edge. Two trajectories leave through the northern, three through the southern, seven through the western, and two through the eastern edge. Five trajectories feed the west-northwestward NBUC after leaving the box, two recurve in the SICC, and one leads southward offshore of the boundary current.

Many of the above interactions between the NICC, EIC, and SICC have already been identified by Stramma and Schott (1999, their fig. 6) based mainly on water mass analysis and transport estimates, and the float trajectories now confirm them by providing direct velocity measurements. Generally, these findings support the interpretation of fig. 8 that all westward current bands (NEIC, EIC, SEIC) have a tendency to add to the northwestward-flowing boundary current, while the eastward current bands (SICC, NICC) strongly drain from an area offshore of the NBUC as well as the NBUC itself. Interior flow from one current band to another is possible but occurs much less frequently than 
at the boundary. The majority of trajectories are consistent with the mean flow.

\subsection{Crossing of the Equator}

The immediate vicinity of the equator is dynamically special in oceanography because the Coriolis force, essential for large-scale motions elsewhere, vanishes there. Richardson and Fratantoni (1999) have described how floats in the uNADW cross the equator southward, and here we take a look at the flow of AAIW across the equator northward. Boebel et al. (1999a) have identified how the northward flow from the NBUC is deflected subsequently in the SICC, EIC, and the NICC, but had to base their results on a very small number of floats. Fig. 12 shows a greatly enlarged database of float trajectories near the equator in the AAIW layer: trajectories of floats with position fixes within $0.5^{\circ}$ of the equator are shown prior to and after exiting this equatorial strip. The main route detraining the strip appears to be the NBUC north of the Equator, based on the number of trajectories that follow its path. However, there seem to be very few trajectories that continuously follow the NBUC from the southern to the northern hemisphere (cf. fig. 8). Trajectories that leave the equatorial strip in the northwestward NBUC tend to originate in the EIC (i. e. within the box from the east) and thereby come from the ocean interior. Elsewhere along the entire strip, no systematic entrainment or detrainment is obvious either to/from the north or to/from the south, although several trajectories leave and enter the box to/from either side in a seemingly random fashion. This corresponds to the interaction of the zonal equatorial current bands - in this case the EIC - with the surroundings, and the mechanism suggested for such interaction is tropical instability waves (Richardson and Fratantoni, 1999). The main inflow into the equatorial box as it is depicted in the figure stems from the east, outside the domain studied here.

To summarize, the major path that carries AAIW northward from the equator is in 
the NBUC, which in turn appears mostly fed from the ocean interior through the EIC. The direct path along the shelf break is possible but rare. Southward flow along the boundary from the equator as shown by Boebel et al. (1999a) is only observed in one case and thus unlikely. Cross-equatorial exchange in either direction can occur in the ocean interior when water enters or leaves the EIC.

\section{Conclusions}

Float data coverage in the AAIW (cf. table 1 for all abbreviations) layer in the northwestern tropical Atlantic is sufficient to map out the mean flow and the properties of the mesoscale eddy field on a basin-wide domain. The AAIW as a water mass enters the domain from the south in the NBUC (Stramma et al., 1995), as well as from the east through three westward-flowing zonal current bands (NEIC, EIC, SEIC) in the equatorial region at latitudes lower than $5^{\circ}$ (e. g. Ollitrault et al., 2006). Between these three, two equatorial currents (NICC, SICC) flow eastward and provide an exit route out of the domain, thereby forming an exchange mechanism between the western and eastern basins. Direct exchange between these opposite flows along their paths is also observed. Mean transports are given in table 3. Fig. 13 (top) shows a schematic of the mean circulation and relates the new findings to previous results. Float trajectories support the circulation schematic presented by Stramma and Schott (1999) for exchange processes between the NICC, EIC, and SICC near the western boundary. The amendment to this schematic by Schmid et al. (2003), who include the NEIC and SEIC, is corrected in some detail as to the location of the NEIC and how the currents interact with each other and especially the boundary. Another export route for AAIW is to the north along the NBUC, and further downstream in a weak mean northward flow paralleling the coast of South America and the Antilles islands mostly 200-400 km offshore of the shelf break. Stramma 
and Schott (1999) include such a pathway but take it into the Caribbean through the southernmost passages, and do not report the continued northward flow in the Atlantic. This flow is heavily masked by mesoscale eddy activity, and a possible interpretation is that the measured mean flow downstream of the NBUC represents the advection speed of North Brazil Current Rings, large anticyclonic eddies that originate from the NBC/NBUC system (Richardson et al., 1994). This interpretation is in quantitative agreement with findings by Rhein et al. (2005), which are based on hydrographic measurements. However, there is no evidence of large-scale gyres in the basin interiors as shown by Stramma and Schott (1999) and Schmid et al. (2003), and these are crossed out accordingly in fig. 13. It remains unclear why floats do not show the inflow into the Caribbean through the southernmost Antilles islands, which is clearly observed by Rhein et al. (2005). A quantitative description of the mesoscale field shows Lagrangian integral time scales between $4 \mathrm{~d}$ and $10 \mathrm{~d}$, and eddy kinetic energies between $20 \mathrm{~cm}^{2} \mathrm{~s}^{-2}$ and $150 \mathrm{~cm}^{2} \mathrm{~s}^{-2}$, with higher energy levels and shorter time scales generally closer to shore. Typical eddy diameters from 70 to greater than $140 \mathrm{~km}$ are derived. The repeated occurrence of cyclones with higher energy levels and smaller spatial scales as initially observed by Fratantoni and Richardson (2006) would motivate a further investigation of eddies in the area between Barbados and the Guiana Plateau.

In the uNADW layer (fig. 13, bottom), the strongest signal is the southward-flowing DWBC, the speed of which varies along the coast. Interaction with the interior is a likely explanation for varying speeds: the data show a slim recirculation east of the Lesser Antilles and a coherent westward (i. e. onshore) flow throughout the basin near $16^{\circ} \mathrm{N}$ observed at least for several months. The source region of the latter remains to be identified but seems to be at or even east of the Mid-Atlantic Ridge. NADW spreading from the subpolar North Atlantic via interior pathways is a likely possibility. A tendency of the DWBC to diverge at $10^{\circ} \mathrm{N}$ is directly observed for the first time and, together 
with the recirculations upstream, is consistent with findings of a dilution of DWBC water as reported by Steinfeldt et al. (2007). South of $10^{\circ}$ N, fig. 13 shows an adaptation of previous results by Richardson and Schmitz (1993) and Richardson and Fratantoni (1999), which include the DWBC and various zonal current bands in the equatorial region which closely resemble those of the AAIW layer. Open questions remain as to how the DWBC signal bridges the gap near $57^{\circ} \mathrm{W}$, the site of the aforementioned divergence. It is also not quantitatively clear how well the equatorial zonal currents resemble those of the AAIW. Both issues suffer from data sparsity, calling for analysis with numerical models. The mean and mesoscale velocities quantified herein may well serve as ground truth for such numerical simulations.

\section{Acknowledgements}

MOVE was funded by the Bundesministerium für Bildung und Forschung (grants 03F0246A and 03F0377B) as well as by the Deutsche Forschungsgemeinschaft (grant SE815/21), NBC by the National Science Foundation through grants OCE 97-29765 and OCE 01-36477, and SAMBA was fully supported by Ifremer. The authors are thankful to all float data providers listed in table 2. M. McCartney has generously shared data from the GAGE moorings. CTD and LADCP data for fig. 2 were kindly supplied by M. Rhein and M. Walter. Argo data were collected and made freely available by the International Argo Project and the national programs that contribute to it. Argo is a pilot program of the Global Ocean Observing System.

Dedication: We dedicate this paper to the memory of the late Friedrich ("Fritz") Schott, whom we remember as a colleague, friend, and scientist with profound interest in the tropical Atlantic. Friedrich Schott's legacy consists of pioneering observational data of the area and accompanying interpretations, including measurements of the western boundary 
currents and the equatorial currents discussed in this paper. Several figures and discussion ${ }_{613}$ points of this work were motivated by questions he raised as a committee member during ${ }_{614}$ ML's doctoral defense. He will remain in our memories as an outstanding, motivated, 615 and quite effervescent scientist. 


\section{References}

Boebel, O., Davis, R. E., Ollitrault, M., Peterson, R. G., Richardson, P. L., Schmid, C., Zenk, W., 1999a. The Intermediate Depth Circulation of the Western South Atlantic. Geophys. Res. Lett. 26 (21), 3329-3332.

Boebel, O., Schmid, C., Zenk, W., 1999b. Kinematic elements of Antarctic Intermediate Water in the western South Atlantic. Deep-Sea Res. II 46 (1-2), 355-392.

Bower, A. S., Cann, B. L., Rossby, T., Zenk, W., Gould, J., Speer, K., Richardson, P. L., Prater, M. D., Zhang, H.-M., 2002. Directly measured mid-depth circulation in the northeastern North Atlantic Ocean. Nature 419, 603-607.

Colin, C., Bourlès, B., Chuchla, R., Dangu, F., 1994. Western boundary current variability off French Guiana as observed from moored current measurements. Oceanologica Acta $17(4), 345-354$.

Curry, R. G., McCartney, M. S., Joyce, T. M., 1998. Oceanic transport of subpolar climate signals to mid-depth subtropical waters. Nature 391, 575-577.

Eden, C., 2006. Middepth equatorial tracer tongues in a model of the Atlantic Ocean. J. Geophys. Res. 111 (C12025).

Fratantoni, D. M., Richardson, P. L., 2006. The Evolution and Demise of North Brazil Current Rings. J. Phys. Oceanogr. 36 (7), 1241-1264.

Getzlaff, K., Böning, C. W., Dengg, J., 2006. Lagrangian perspectives of deep water export from the subpolar North Atlantic. Geophys. Res. Lett. 33 (L21S08).

Goni, G. J., Johns, W. E., 2001. A Census of North Brazil Current Rings Observed from TOPEX/POSEIDON Altimetry: 1992-1998. Geophys. Res. Lett. 28 (1), 1-4. 
Gouriou, Y., Andrié, C., Bourlès, B., Freudenthal, S., Arnault, S., Aman, A., Eldin, G., du Penhoat, Y., Baurand, F., Gallois, F., Chuchla, R., 2001. Deep Circulation in the Equatorial Atlantic Ocean. Geophys. Res. Lett. 28 (5), 819-822.

Jochum, M., Malanotte-Rizzoli, P., 2003. Interhemispheric Water Exchange in the Atlantic Ocean (Eds.: G. J. Goni and P. Malanotte-Rizzoli). Elsevier, Ch. The flow of AAIW along the equator, pp. 193-212.

Johns, W. E., Lee, T. N., Beardsley, R. C., Candela, J., Limeburner, R., Castro, B., 1998. Annual Cycle and Variability of the North Brazil Current. J. Phys. Oceanogr. 28 (1), $103-128$.

Johns, W. E., Lee, T. N., Schott, F. A., Zantopp, R. J., Evans, R. H., 1990. The North Brazil Current Retroflection: Seasonal Structure and Eddy Variability. J. Geophys. Res. 95 (C12), 22103-22120.

Johns, W. E., Zantopp, R. J., Goni, G. J., 2003. Interhemispheric Water Exchange in the Atlantic Ocean (Eds.: G. J. Goni and P. Malanotte-Rizzoli). Elsevier, Ch. Cross-gyre transport by North Brazil Current Rings, pp. 411-441.

Kirchner, K., Rhein, M., Mertens, C., Böning, C. W., Hüttl, S., 2008. Observed and modeled meridional overturning circulation related flow into the Caribbean. J. Geophys. Res. 113 (C03028).

Lankhorst, M., Zenk, W., 2006. Lagrangian Observations of the Middepth and Deep Velocity Fields of the Northeastern Atlantic Ocean. J. Phys. Oceanogr. 36 (1), 43-63.

Machín, F., Send, U., Zenk, W., 2006. Intercomparing drifts from RAFOS and profiling floats in the deep western boundary current along the Mid-Atlantic Ridge. Scientia Marina $70(1), 1-8$. 
Marshall, J., Kushnir, Y., Battisti, D., Chang, P., Czaja, A., Dickson, R., Hurrell, J., McCartney, M., Saravanan, R., Visbeck, M., 2001. North Atlantic climate variability: phenomena, impacts and mechanisms. Int. J. Climatol. 21 (15), 1863-1898.

Ollitrault, M., Lankhorst, M., Fratantoni, D., Richardson, P., Zenk, W., 2006. Zonal intermediate currents in the equatorial Atlantic Ocean. Geophys. Res. Lett. 33, L05605.

Paillet, J., Arhan, M., McCartney, M. S., 1998. Spreading of Labrador Sea Water in the eastern North Atlantic. J. Geophys. Res. 103 (C5), 10223-10239.

Rhein, M., Kirchner, K., Mertens, C., Steinfeldt, R., Walter, M., Fleischmann-Wischnath, U., 2005. Transport of South Atlantic water through the passages south of Guadeloupe and across $16^{\circ} \mathrm{N}, 2000-2004$. Deep-Sea Res. I 52, 2234-2249.

Rhein, M., Stramma, L., Send, U., 1995. The Atlantic Deep Western Boundary Current: Water masses and transports near the equator. J. Geophys. Res. 100 (C2), 2441-2457.

Rhein, M., Walter, M., Mertens, C., Steinfeldt, R., Kieke, D., 2004. The circulation of North Atlantic Deep Water at 16 N, 2000-2003. Geophys. Res. Lett. 31 (L14305).

Richardson, P. L., Fratantoni, D. M., 1999. Float trajectories in the deep western boundary current and deep equatorial jets of the tropical Atlantic. Deep-Sea Res. II 46 (1-2), $305-333$.

Richardson, P. L., Hufford, G. E., Limeburner, R., 1994. North Brazil Current retroflection eddies. J. Geophys. Res. 99 (C3), 5081-5093.

Richardson, P. L., Schmitz, Jr., W. J., 1993. Cross-Equatorial Flow in the Atlantic Measured With SOFAR Floats. J. Geophys. Res. 98, 8371-8387.

Rossby, T., 2007. Lagrangian Analysis and Prediction of Coastal and Ocean Dynamics 
(Eds.: A. Griffa, A. D. Kirwan, A. J. Mariano, T. Özgökmen, and T. Rossby). Cambridge University Press, Ch. "Evolution of Lagrangian Methods in Oceanography".

Rossby, T., Price, J., Webb, D., 1986. The Spatial and Temporal Evolution of a Cluster of SOFAR Floats in the POLYMODE Local Dynamics Experiment (LDE). J. Phys. Oceanogr. 16 (3), 428-442.

Schmid, C., Bourlès, B., Gouriou, Y., 2005. Impact of the equatorial deep jets on estimates of zonal transports in the Atlantic. Deep-Sea Res. II 52, 409-428.

Schmid, C., Garaffo, Z., Johns, E., Garzoli, S. L., 2003. Interhemispheric Water Exchange in the Atlantic Ocean (Eds.: G. J. Goni and P. Malanotte-Rizzoli). Elsevier, Ch. Pathways and variability at intermediate depths in the tropical Atlantic, pp. 233-268.

Schott, F., Fischer, J., Reppin, J., Send, U., 1993. On Mean and Seasonal Currents and Transports at the Western Boundary of the Equatorial Atlantic. J. Geophys. Res. 98 (C8), 14353-14368.

Schott, F. A., Dengler, M., Brandt, P., Affler, K., Fischer, J., Bourlès, B., Gouriou, Y., Molinari, R. L., Rhein, M., 2003. The zonal currents and transports at $35^{\circ} \mathrm{W}$ in the tropical Atlantic. Geophys. Res. Lett. 30 (7).

Schott, F. A., Fischer, J., Stramma, L., 1998. Transports and Pathways of the Upper-Layer Circulation in the Western Tropical Atlantic. J. Phys. Oceanogr. 28 (10), 1904-1928.

Send, U., Kanzow, T., Zenk, W., Rhein, M., 2002. Monitoring the Atlantic Meridional Overturning Circulation at $16^{\circ}$ N. CLIVAR Exchanges 7 (3/4), 31-33.

Speer, K. G., Gould, J., LaCasce, J., 1999. Year-long float trajectories in the Labrador Sea Water of the eastern North Atlantic Ocean. Deep-Sea Res. II 46 (1-2), 165-179. 
Steinfeldt, R., Rhein, M., Walter, M., 2007. NADW transformation at the western boundary between $66^{\circ} \mathrm{W} / 20^{\circ} \mathrm{N}$ and $60^{\circ} \mathrm{W} / 10^{\circ} \mathrm{N}$. Deep-Sea Res. I 54, 835-855.

Stramma, L., England, M., 1999. On the water masses and mean circulation of the South Atlantic Ocean. J. Geophys. Res. 104 (C9), 20863-20883.

Stramma, L., Fischer, J., Reppin, J., 1995. The North Brazil Undercurrent. Deep-Sea Res. I 42 (5), 773-795.

Stramma, L., Rhein, M., Brandt, P., Dengler, M., Böning, C., Walter, M., 2005. Upper ocean circulation in the western tropical Atlantic in boreal fall 2000. Deep-Sea Res. I $52(2), 221-240$.

Stramma, L., Schott, F., 1999. The mean flow field of the tropical Atlantic Ocean. DeepSea Res. II 46 (1-2), 279-303.

Talley, L. D., 1996. The South Atlantic: Present and Past Circulation (Eds.: Gerold Wefer, Wolfgang H. Berger, Gerold Siedler, D. J. Webb). Springer, Ch. Antarctic Intermediate Water in the South Atlantic. 
Table 1: List of abbreviations.

$\begin{array}{ll}\text { AAIW } & \text { Antarctic Intermediate Water } \\ \text { ACCE } & \text { Atlantic Circulation and Climate Experiment } \\ \text { CTD } & \text { Conductivity-Temperature-Depth } \\ \text { EIC } & \text { Equatorial Intermediate Current } \\ \text { EKE } & \text { Eddy Kinetic Energy } \\ \text { IFM-GEOMAR } & \text { Leibniz-Institut für Meereswissenschaften } \\ \text { Ifremer } & \text { Institut français de recherche pour l'exploitation de la mer } \\ \text { LADCP } & \text { Lowered Acoustic Doppler Current Profiler } \\ \text { MOC } & \text { Meridional Overturning Circulation } \\ \text { MOVE } & \text { Meridional Overturning Variability Experiment } \\ \text { NADW } & \text { North Atlantic Deep Water } \\ \text { NBC, NBUC } & \text { North Brazil (Under-) Current } \\ \text { NEIC } & \text { Northern Equatorial Intermediate Current } \\ \text { NICC } & \text { Northern Intermediate Countercurrent } \\ \text { RAFOS } & \text { SOFAR backwards, Ranging and Fixing of Sound } \\ \text { RSMAS } & \text { Rosenstiel School of Marine and Atmospheric Science } \\ \text { SAMBA } & \text { Subantarctic Motions in the Brazil Basin } \\ \text { SEIC } & \text { Southern Equatorial Intermediate Current } \\ \text { SICC } & \text { Southern Intermediate Countercurrent } \\ \text { SOFAR } & \text { Sound Fixing and Ranging } \\ \text { Tint } & \text { Lagrangian Integral Time Scale } \\ \text { uNADW } & \text { upper North Atlantic Deep Water } \\ \text { WFDAC } & \text { WOCE Subsurface Float Data Assembly Center } \\ \text { WHOI } & \text { Woods Hole Oceanographic Institution } \\ \text { WOCE } & \text { World Ocean Circulation Experiment } \\ & \end{array}$


Table 2: List of data used in this study. Note that some projects have collected more data than is actually used here. WFDAC refers to the WOCE float data center at wfdac.whoi.edu. Where individual persons are listed, the data was obtained directly from them rather than through WFDAC. From SOFAR floats, only the first year of data is used because of ballasting problems presumably worsening with age (Richardson and Fratantoni, 1999). Argo drift pressures are based on nominal rather than measured values.

\begin{tabular}{|c|c|c|c|c|c|c|c|}
\hline $\begin{array}{l}\text { Project } \\
\text { Name }\end{array}$ & $\begin{array}{l}\text { Float } \\
\text { Type }\end{array}$ & $\begin{array}{l}\text { Principal } \\
\text { Investigators }\end{array}$ & Data Source & $\begin{array}{l}\text { Data A } \\
\text { AAIW }\end{array}$ & $\begin{array}{l}\text { ount [d] } \\
\text { uNADW }\end{array}$ & $\begin{array}{l}\text { Press. [dbar] } \\
\text { Mean } \pm \text { Std. }\end{array}$ & $\begin{array}{l}\text { Sampling } \\
\text { Period }\end{array}$ \\
\hline MOVE & $\begin{array}{l}\text { Acoustic } \\
\text { (RAFOS) }\end{array}$ & $\begin{array}{l}\text { U. Send, } \\
\text { W. Zenk }\end{array}$ & $\begin{array}{l}\text { IFM-GEOMAR, } \\
\text { M. Lankhorst }\end{array}$ & 4370 & 2410 & $\begin{array}{l}811 \pm 30 \\
1433 \pm 125\end{array}$ & $\begin{array}{l}2000-2001 \\
2001-2001\end{array}$ \\
\hline NBC & $\begin{array}{l}\text { Acoustic } \\
\text { (RAFOS) }\end{array}$ & $\begin{array}{l}\text { D. Fratantoni, } \\
\text { P. Richardson }\end{array}$ & $\begin{array}{l}\text { WFDAC, } \\
\text { C. Wooding }\end{array}$ & 3030 & 0 & $861 \pm 60$ & 1998-2000 \\
\hline SAMBA & $\begin{array}{l}\text { Acoustic } \\
\text { (Marvor) }\end{array}$ & $\begin{array}{l}\text { M. Ollitrault, } \\
\text { A. C. de Verdière }\end{array}$ & $\begin{array}{l}\text { Ifremer, } \\
\text { M. Ollitrault }\end{array}$ & 18953 & 0 & $813 \pm 26$ & 1994-2003 \\
\hline $\begin{array}{l}\text { IFM } \\
\text { WOCE-era }\end{array}$ & $\begin{array}{l}\text { Acoustic } \\
\text { (RAFOS) }\end{array}$ & $\begin{array}{l}\text { O. Boebel, } \\
\text { W. Zenk }\end{array}$ & $\begin{array}{l}\text { WFDAC, } \\
\text { M. Lankhorst }\end{array}$ & 930 & 0 & $833 \pm 29$ & 1994-1996 \\
\hline $\begin{array}{l}\text { Trop. Atl. } \\
\text { SOFAR }\end{array}$ & $\begin{array}{l}\text { Acoustic } \\
\text { (SOFAR) }\end{array}$ & $\begin{array}{l}\text { P. Richardson, } \\
\text { W. Schmitz }\end{array}$ & WFDAC & 4610 & 3890 & $\begin{array}{l}839 \pm 72 \\
1863 \pm 39\end{array}$ & $\begin{array}{l}1989-1990 \\
1989-1990\end{array}$ \\
\hline Argo & Profiling & Multiple & $\begin{array}{ll}\text { Argo Data } \\
\text { Centers }\end{array}$ & 37509 & 5975 & $\begin{array}{l}1000 \pm 50 \\
1750 \pm 250\end{array}$ & $\begin{array}{l}1997-2006 \\
2000-2006\end{array}$ \\
\hline $\begin{array}{l}\text { ACCE } \\
\text { (WHOI) }\end{array}$ & Profiling & R. Schmitt & $\begin{array}{l}\text { WFDAC, } \\
\text { E. Montgomery }\end{array}$ & 16351 & 99 & $\begin{array}{l}981 \pm 45 \\
1247 \pm 39\end{array}$ & $\begin{array}{l}1997-2002 \\
1998-2002\end{array}$ \\
\hline $\begin{array}{l}\text { ACCE } \\
\text { (RSMAS) }\end{array}$ & Profiling & K. Leaman & $\begin{array}{l}\text { WFDAC, } \\
\text { P. Vertes }\end{array}$ & 9659 & 3459 & $\begin{array}{l}927 \pm 114 \\
1251 \pm 38\end{array}$ & $\begin{array}{l}1997-2002 \\
1998-2002\end{array}$ \\
\hline
\end{tabular}


Table 3: Mean transports in Sv for current features in the AAIW layer from different studies in relation to this one. All values are adapted to a common layer thickness of $450 \mathrm{~m}$.

\begin{tabular}{|c|c|c|c|c|c|c|c|c|}
\hline & Method & $\begin{array}{l}\text { NBUC } \\
\text { at } 8^{\circ} \mathrm{S}\end{array}$ & SEIC & SICC & EIC & NICC & NEIC & $\begin{array}{l}\text { across } \\
16^{\circ} \mathrm{N}\end{array}$ \\
\hline this study & floats & 5.0 & 2.7 & 4.1 & 3.2 & 4.5 & 3.2 & 3.7 \\
\hline Ollitrault et al. (2006) & floats (800 dbar) & - & 4.7 & 5.4 & 3.9 & 5.8 & 2.5 & - \\
\hline Rhein et al. (2005) & ring count, hydrography & - & - & - & - & - & - & $2.9-4.5$ \\
\hline Schott et al. (2003) & ship LADCP & \multicolumn{2}{|c|}{5.7} & 3.5 & 5.5 & 3.9 & 3.9 & - \\
\hline Boebel et al. (1999a) & floats & 4.5 & - & - & - & - & - & - \\
\hline Schott et al. (1998) & misc. shipborne & $6.4-7.8$ & - & 5.5 & 14.2 & 7.7 & - & - \\
\hline
\end{tabular}



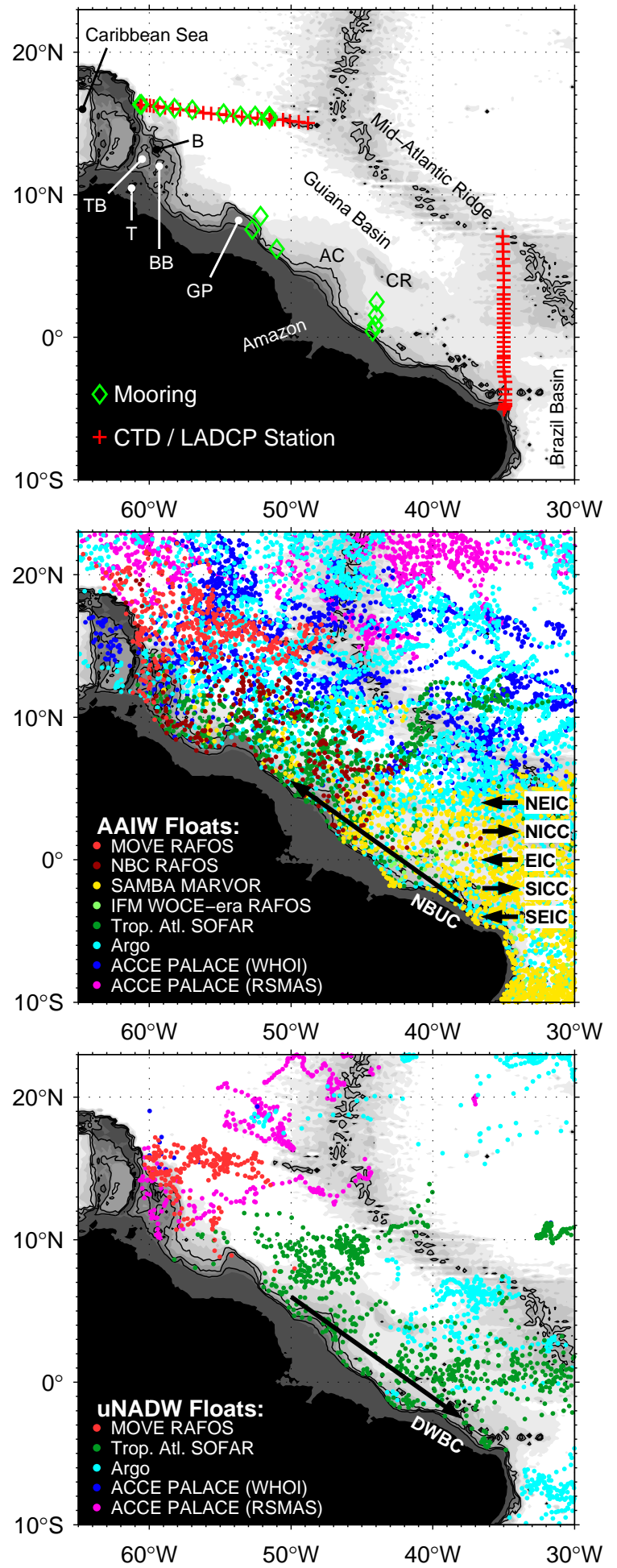

Figure 1: Top: Map of the study area indicating locations of two CTD sections (cf. fig. 2) and various mooring locations (cf. figs. 5 and 6). Abbreviations are: AC Amazon Cone, B Barbados, BB Barbados Basin, CR Ceará Ridge, GP Guiana Plateau, T Trinidad, TB Tobago Basin. Bathymetry in grey shades every $500 \mathrm{~m}$ down to $4500 \mathrm{~m}$ with additional lines at 1000, 2000, and $3000 \mathrm{~m}$.

Middle and bottom: Float data coverage in the AAIW (middle panel) and uNADW (bottom) layers. Colors indicate different research projects. Each dot represents one displacement of typically $10 \mathrm{~d}$ duration. Schematics of major currents are included; cf. table 1 for abbreviations. 

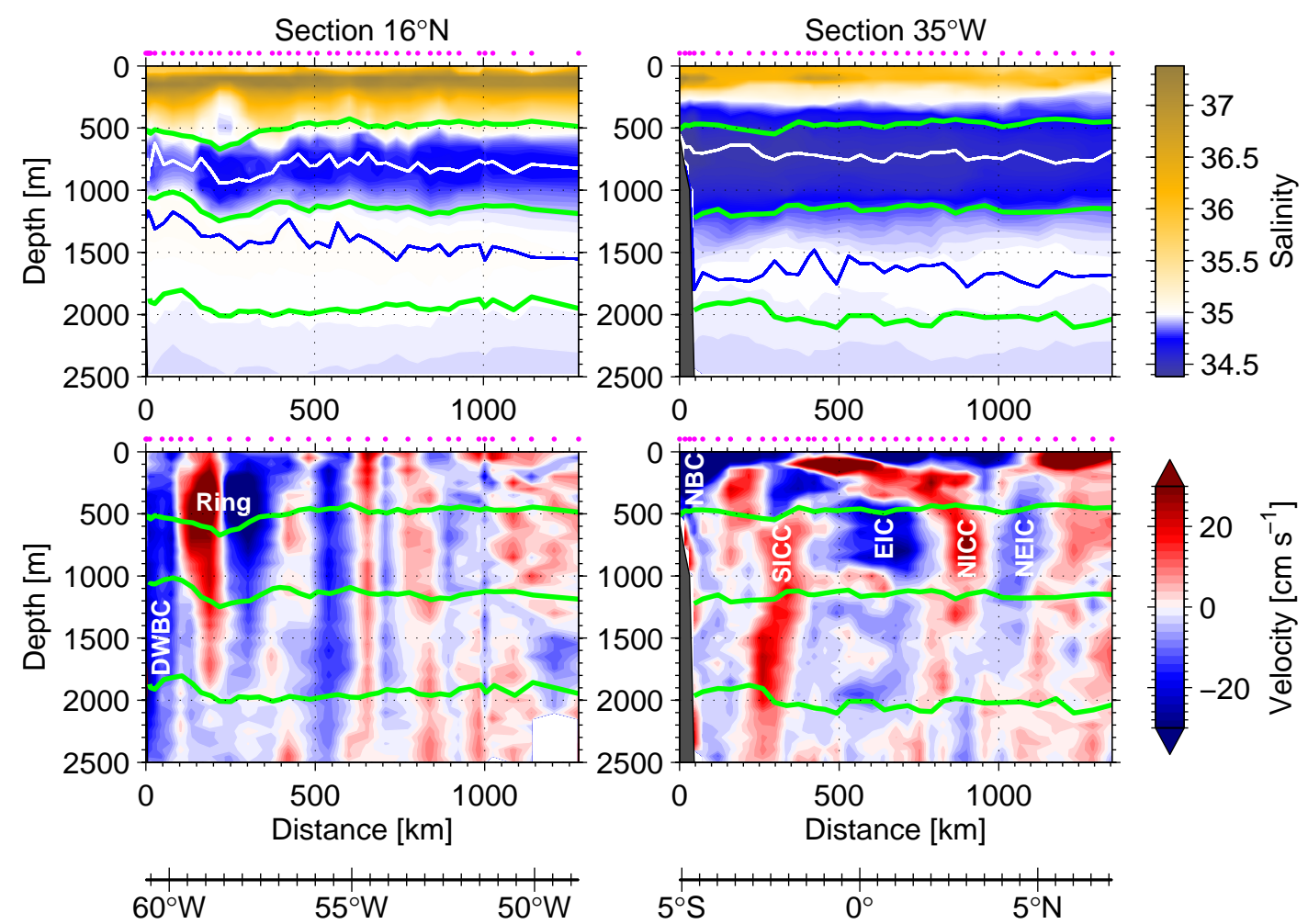

Figure 2: CTD and LADCP sections sampled during RV Sonne cruise 152 in late 2000 (Rhein et al., 2004, 2005). For locations of the two sections, cf. fig. 1: left-hand panels refer to the section near $16^{\circ} \mathrm{N}$, and right-hand panels to the one along $35^{\circ} \mathrm{W}$. Top: Salinity measurements from the CTD. Bottom: Across-section velocities from the LADCP (northand eastward positive), and matching geographic coordinates. Purple dots indicate station locations, and the colored lines denote: depth of minimum salinity in the AAIW (white), depth of local salinity maximum in the uNADW (blue), and isopycnals $\sigma_{0}=27.10$, $\sigma_{1.5}=34.42$, and $\sigma_{1.5}=34.70$ (green) representing AAIW and uNADW boundaries. Labeled current features are discussed in the text (cf. table 1 for abbreviations). 


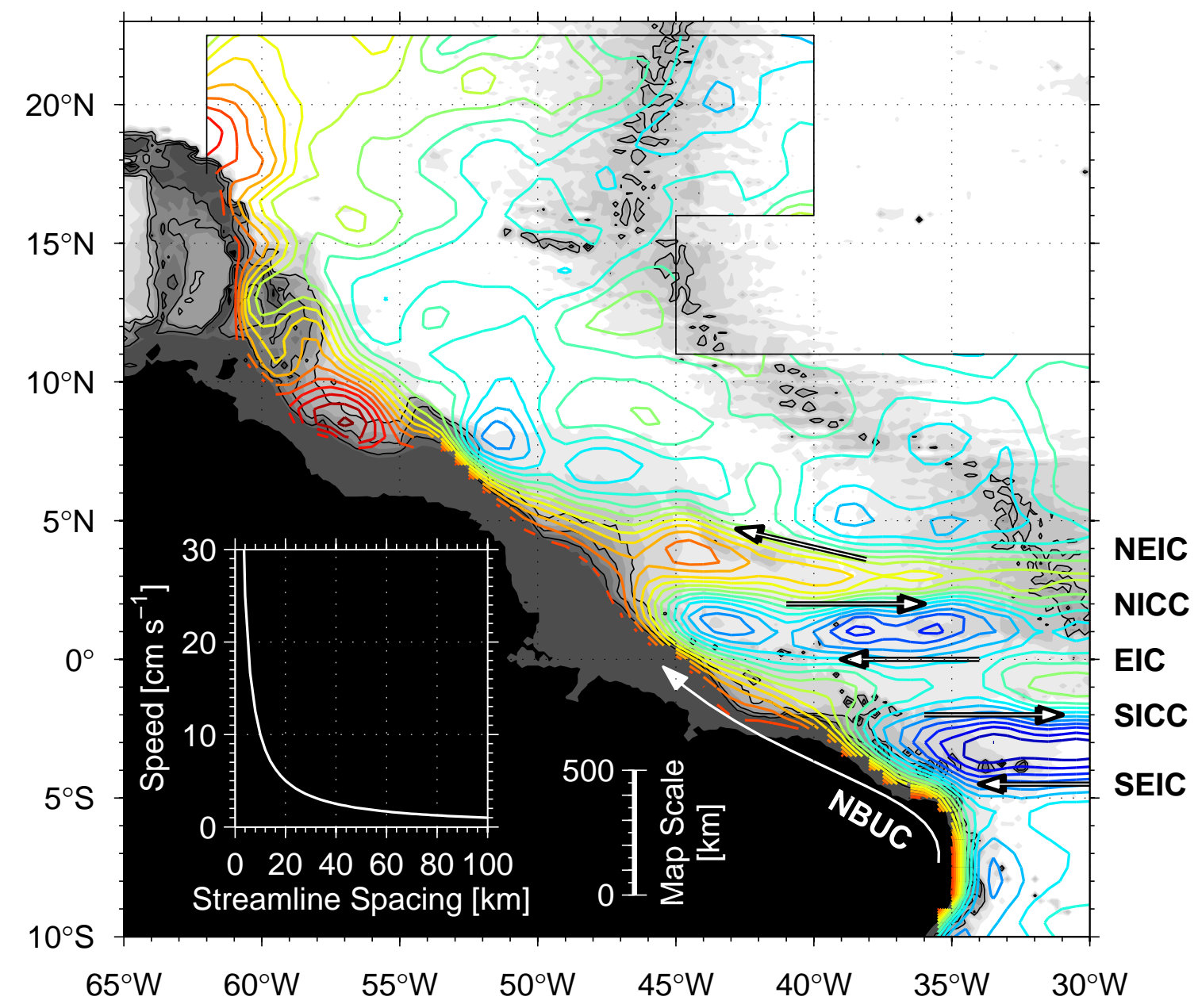

Figure 3: Stream function derived from all float displacements in the AAIW layer. The direction of flow is counterclockwise around reddish features and clockwise around blue ones. Streamline spacing is $1000 \mathrm{~m}^{2} \mathrm{~s}^{-1}$, yielding a volume transport of $0.1 \mathrm{~Sv}$ between two streamlines for every $100 \mathrm{~m}$ of layer thickness. Cf. table 1 for abbreviations of named currents. Bathymetry as in fig. 1. 


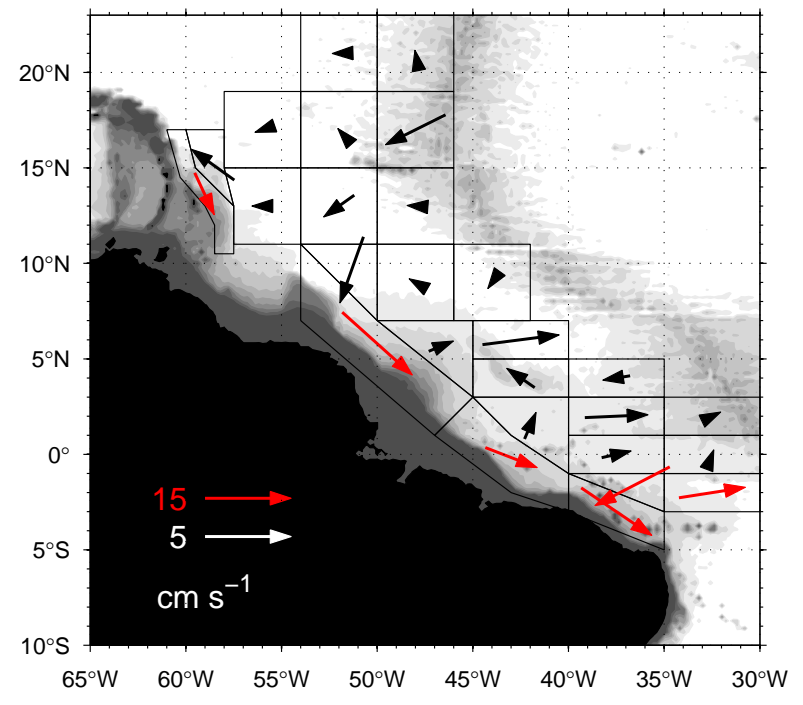

Figure 4: Mean currents in the uNADW layer. Box shapes near the boundary follow the flow features seen in individual trajectories (fig. 9). Arrow colors indicate scale. Bathymetry in shades of grey every $500 \mathrm{~m}$ down to $4500 \mathrm{~m}$. 

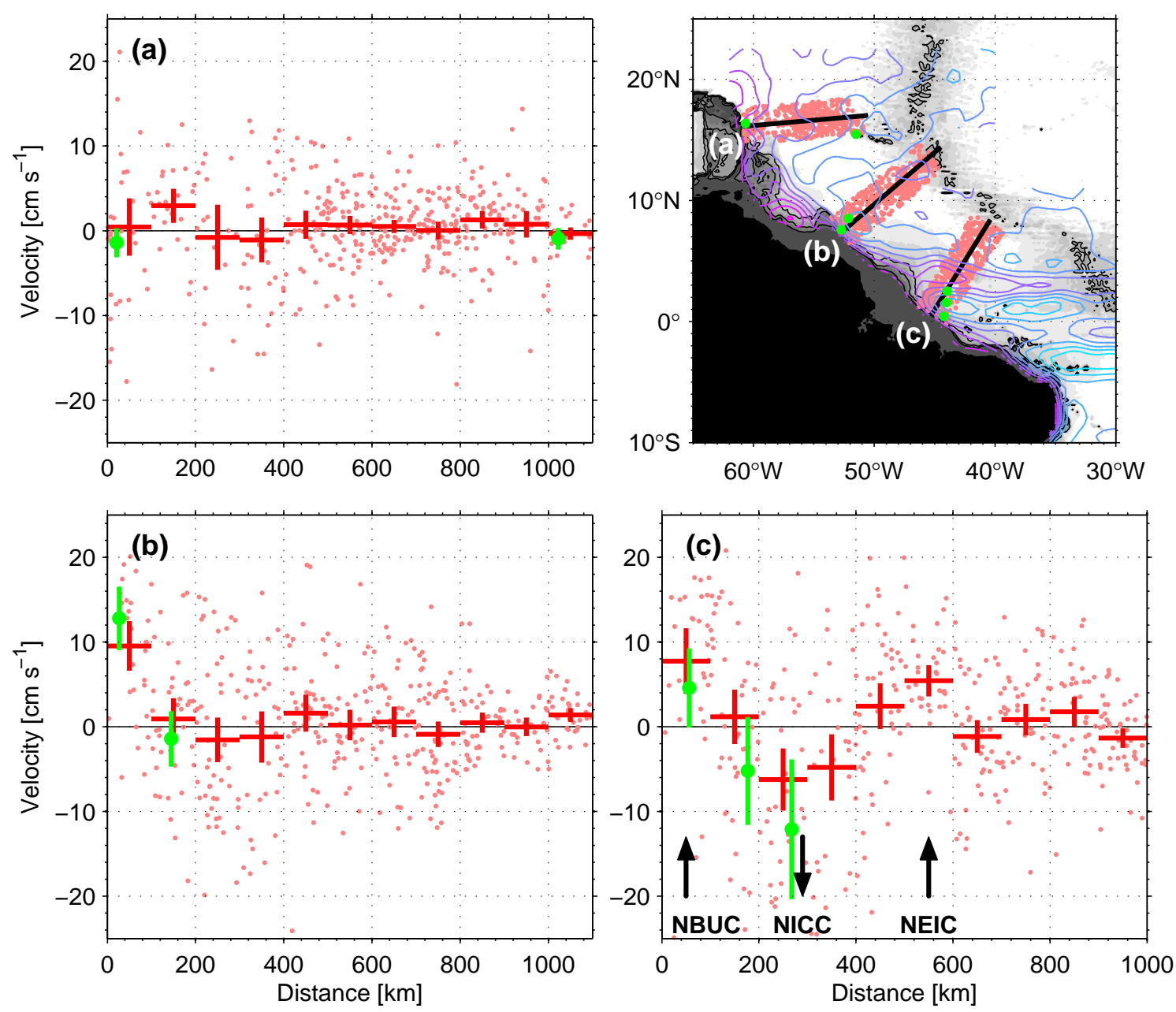

Figure 5: Velocities across three sections in the AAIW layer derived from float displacements (red) and mooring records (green). Upper right: Map with the sections (black lines), locations of data collection (red and green), and the stream function of fig. 3 (bluish, spaced every $2000 \mathrm{~m}^{2} \mathrm{~s}^{-1}$ ) superimposed. Other panels: Light red dots refer to individual float displacements of typically ten days duration. Red crosses average these values in bins of $100 \mathrm{~km}$; vertical extents of the crosses indicate $95 \%$ confidence intervals. Mooring data are shown as green dots with $95 \%$ confidence limits. Mooring data are from (a) the MOVE experiment, (b) Johns et al. (1990), and (c) Schott et al. (1993). Abbreviations in (c) refer to named currents (cf. table 1). 

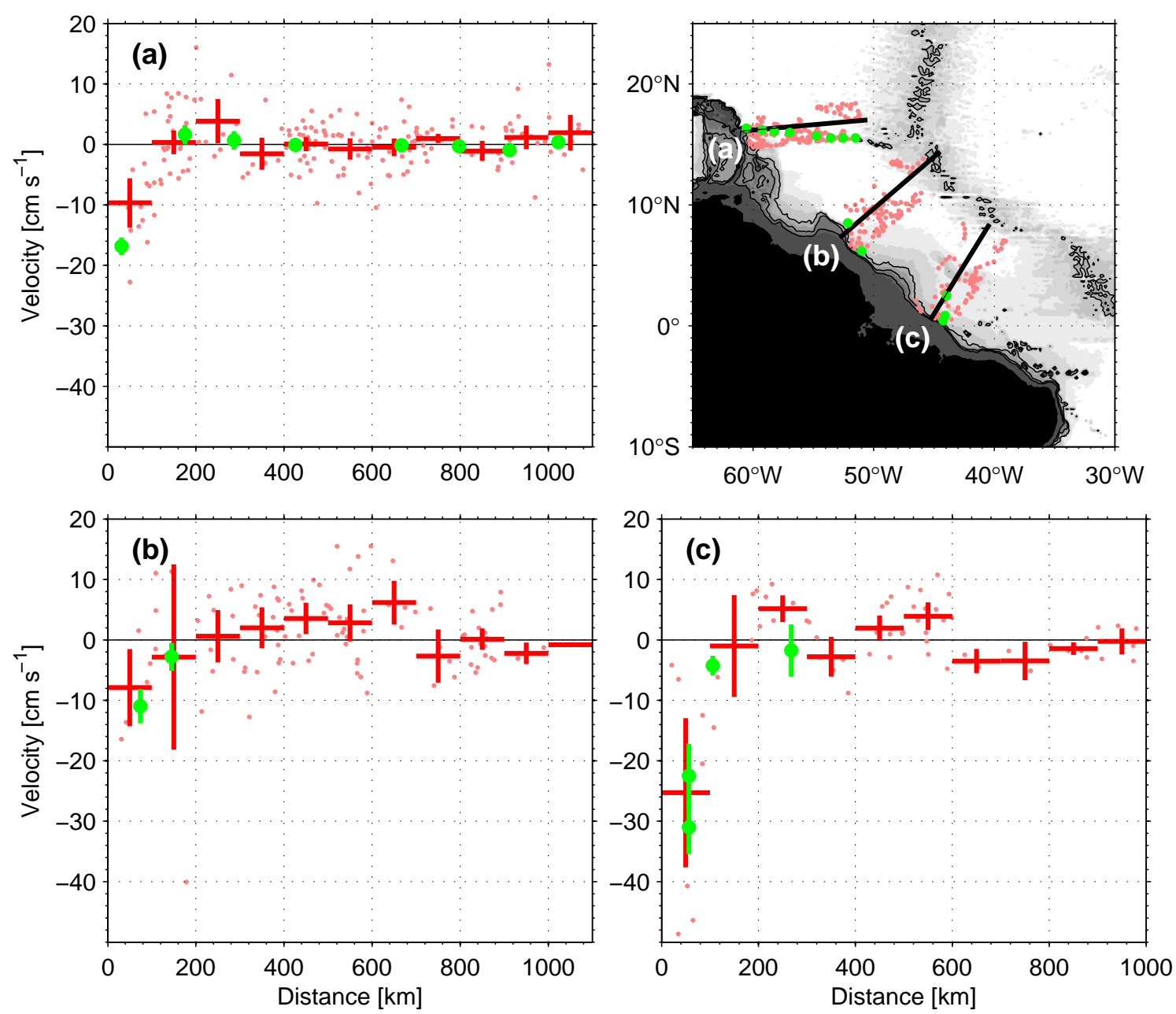

Figure 6: Velocities across three sections in the uNADW layer (otherwise as fig. 5) derived from float displacements (red) and mooring records (green). Mooring data are from (a) the MOVE and GAGE (M. McCartney, pers. comm.) experiments, (b) from Johns et al. (1990) and Colin et al. (1994), and (c) from Schott et al. (1993). 

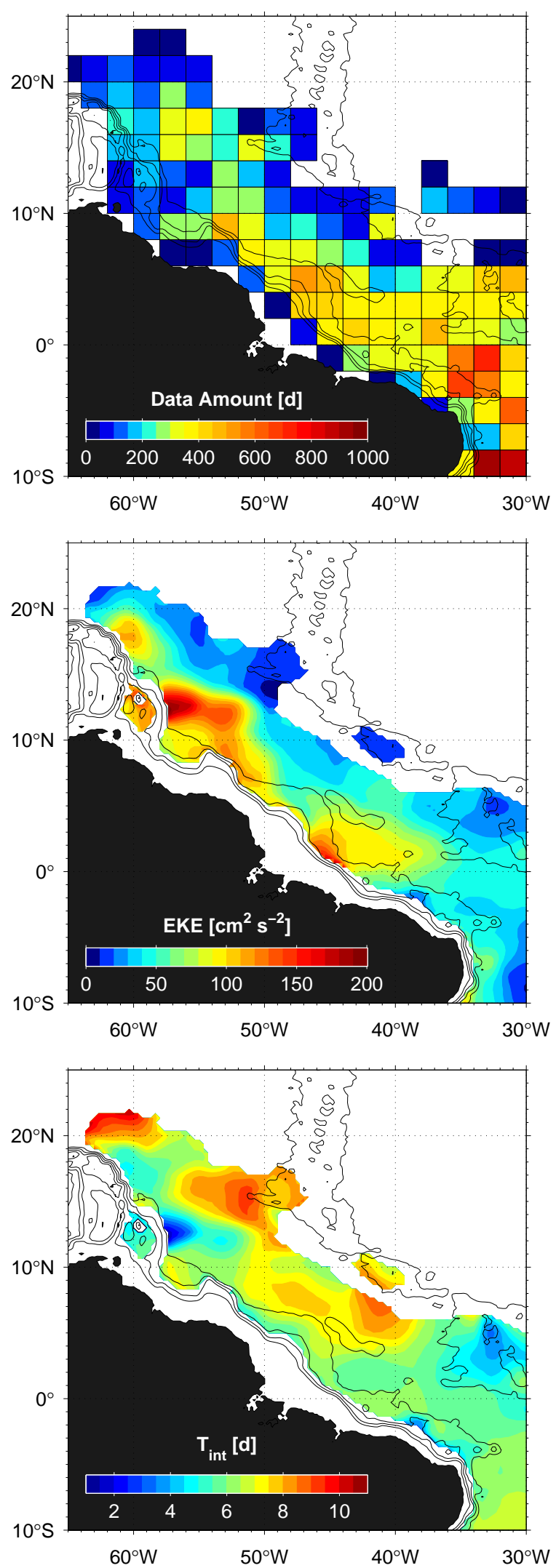

Figure 7: Lagrangian properties of the eddy field in the AAIW layer derived from float data with daily underwater positioning. Top: Data coverage in cumulative float days. Middle: Lagrangian eddy kinetic energy (EKE). Bottom: Lagrangian integral time scale $\left(\mathrm{T}_{\text {int }}\right)$. Bathymetric contours are at every $1000 \mathrm{~m}$ down to $4000 \mathrm{~m}$. 

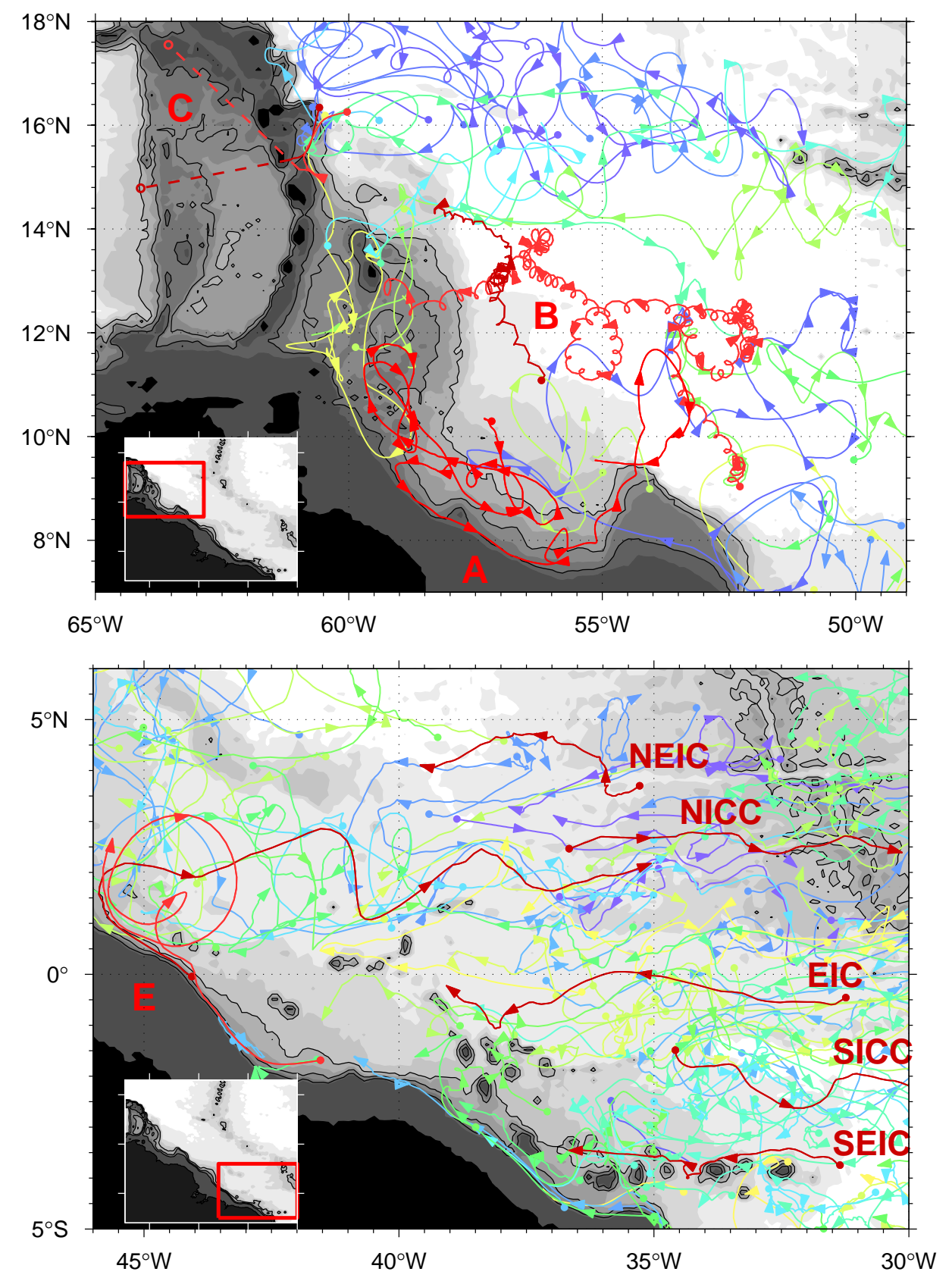

Figure 8: Eddy-resolving float trajectories of the AAIW layer. The selection is limited to acoustic floats from the MOVE, NBC, and SAMBA projects for which tracking was of good quality. Dots are at start points, arrow tips are $30 \mathrm{~d}$ apart. Single letters refer to highlighted (red) trajectories discussed in the text (section 4.1), abbreviations to named currents (cf. table 1). Bathymetry as in fig. 1. 

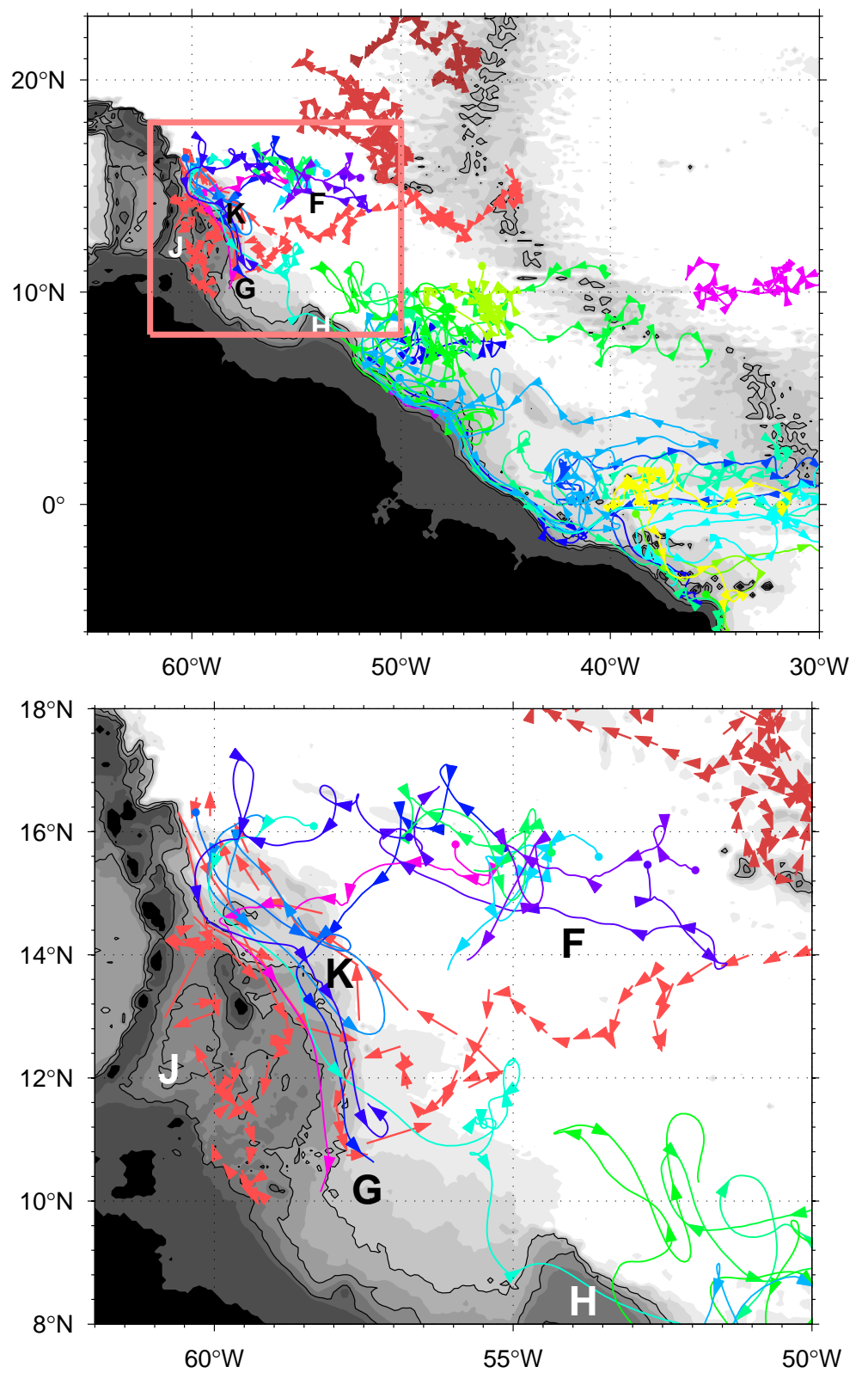

Figure 9: Selected float trajectories of the uNADW layer. Trajectories are from three profiling floats (ACCE RSMAS, shades of red) and the eddy-resolving acoustic MOVE and SOFAR float projects (other colors). Arrows for the profiling floats show their ten-day displacements, and arrow tips in the acoustic trajectories are $30 \mathrm{~d}$ apart. Letters refer to trajectories discussed in the text (section 4.1). The bottom panel is a close-up of the box marked in the top panel. Bathymetry as in fig. 1. 


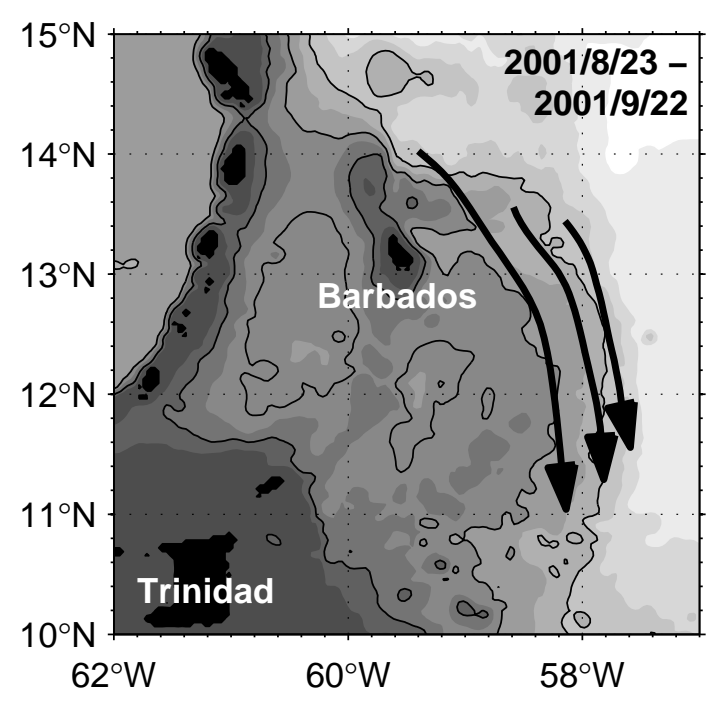

Figure 10: Snapshot of three simultaneous float trajectories drifting at 1400 dbar in the southward-flowing DWBC east of Barbados. The drift time was one month, yielding mean currents of $14.6,10.7$, and $8.6 \mathrm{~cm} \mathrm{~s}^{-1}$ for the three trajectory segments. Bathymetry as in fig. 1. 

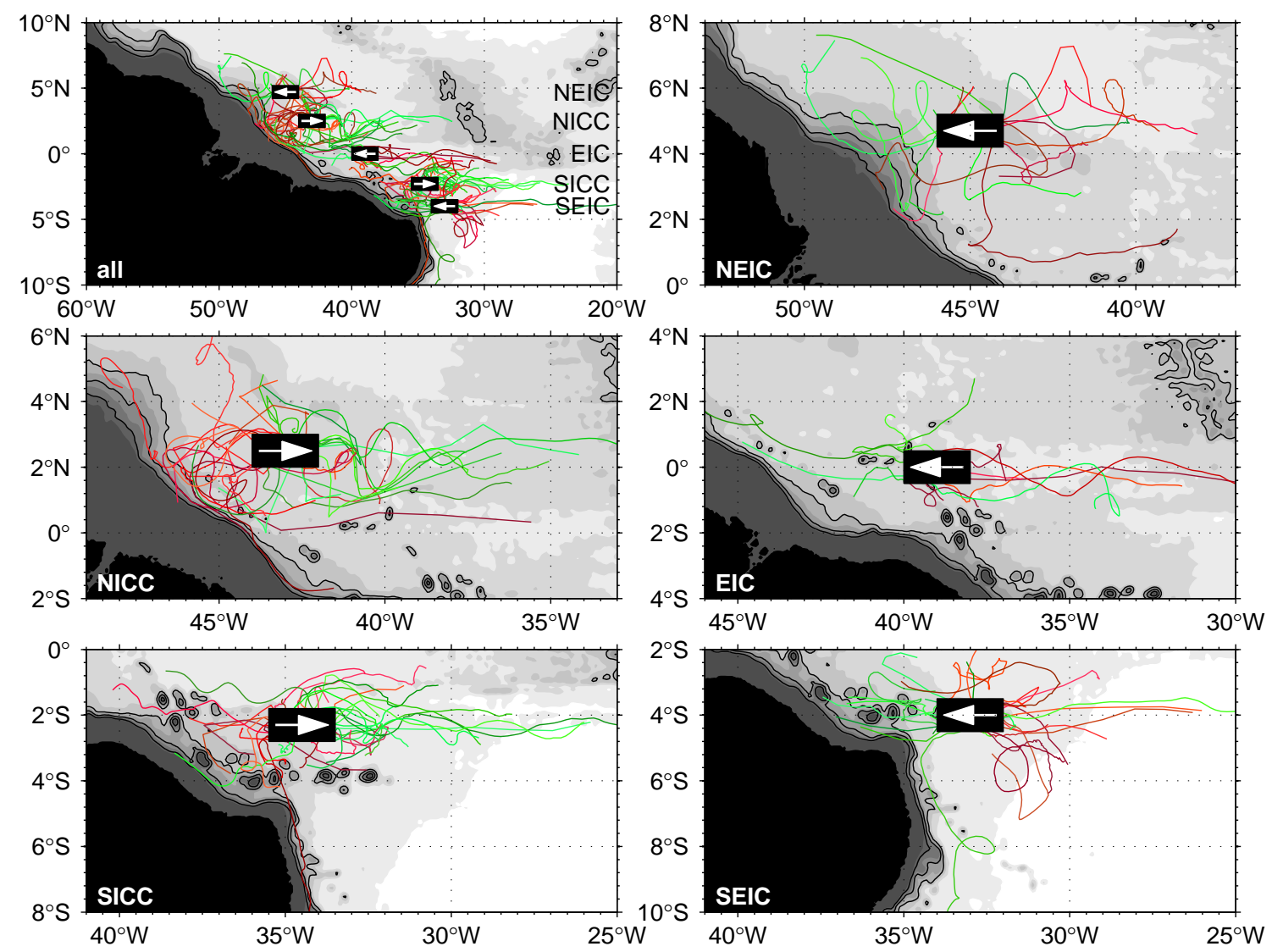

Figure 11: Interaction between the zonal equatorial currents and the boundary. Trajectories that pass through the black boxes are displayed. Red shades represent trajectories up to $80 \mathrm{~d}$ before entering the box, and green shades are trajectories up to $80 \mathrm{~d}$ after leaving the box. Top left panel: All boxes and trajectories superimposed. Other panels: Close-ups of individual boxes and corresponding trajectories. Boxes are designed to represent the following currents (cf. fig. 3): NEIC, NICC, EIC, SICC, SEIC. Arrows in the boxes indicate whether mean flow is generally east- or westward in the current band. Bathymetry as in fig. 1, abbreviations as in table 1. 


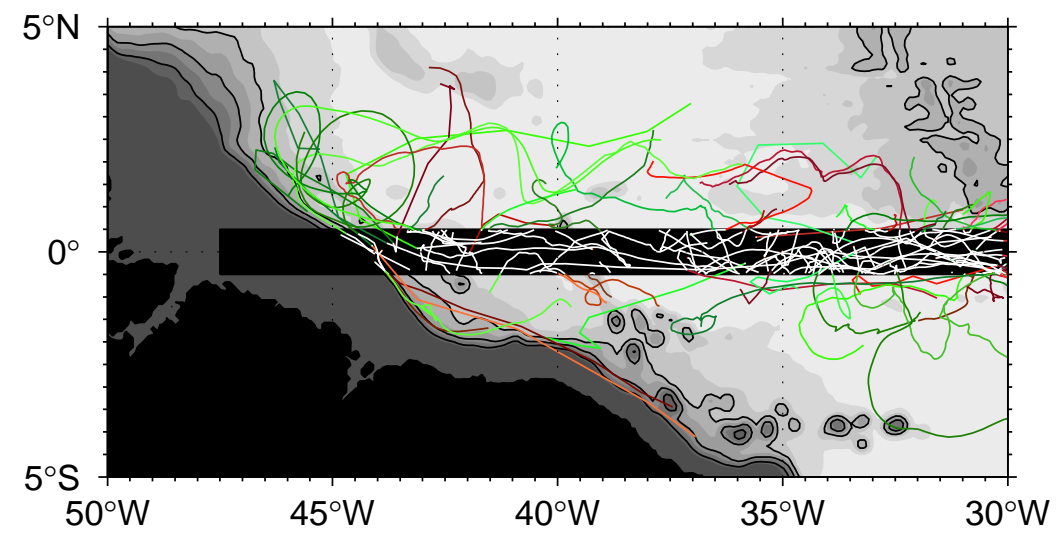

Figure 12: Crossing of the equator in the AAIW layer. Like in fig. 11, float trajectory segments up to $80 \mathrm{~d}$ in duration before entering (red) and after leaving (green) the black box are displayed. Trajectory segments in the box are included in white. Bathymetry as in fig. 1. 

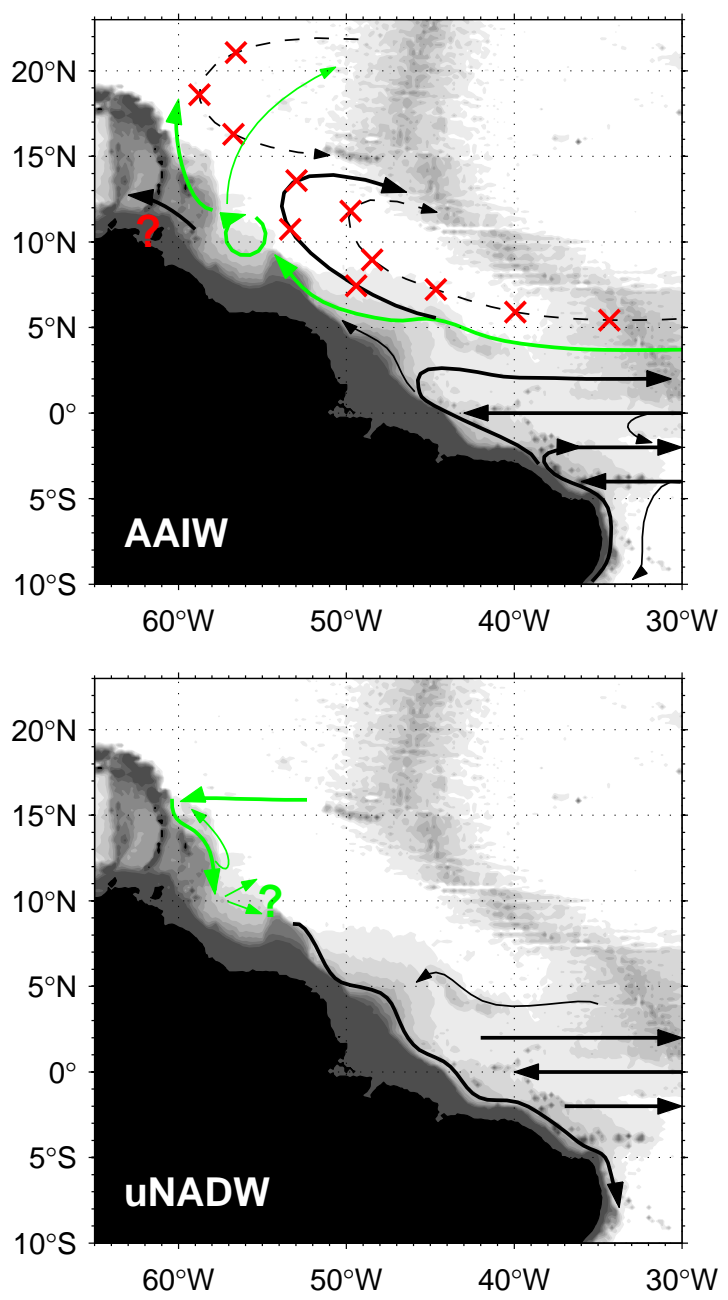

Figure 13: Circulation schematics. Top: AAIW layer. Black arrows reproduce results by Stramma and Schott (1999) and Schmid et al. (2003). Green arrows correct and extend these. Red marks show where the previous results were disproven. Bottom: uNADW layer. Black arrows interpret results by Richardson and Fratantoni (1999). Green arrows show findings based on the present study. 